22

29

30

\title{
Implication of synaptotagmins 4 and 7 in activity-dependent somatodendritic dopamine release
}

\section{Benoît Delignat-Lavaud ${ }^{1,2,3}$, Charles Ducrot ${ }^{1,2,3}$, Willemieke Kouwenhoven ${ }^{1,2,3}$, Nina} Feller $^{1,2,3}$, Louis-Éric Trudeau ${ }^{1,2,3}$

\author{
${ }^{1}$ Department of Pharmacology and Physiology, Faculty of Medicine, Université de \\ Montréal \\ ${ }^{2}$ Department of Neurosciences, Faculty of Medicine, Université de Montréal \\ ${ }^{3}$ CNS Research Group (GRSNC), \\ Montréal, QC, Canada H3C 3J7
}

\author{
Corresponding author: \\ Dr. Louis-Éric Trudeau \\ Department of pharmacology and physiology \\ Faculty of Medicine \\ Université de Montréal \\ louis-eric.trudeau@umontreal.ca \\ 514-343-5692
}




\section{ABSTRACT}

32

33

34 from their somatodendritic (STD) compartment thought a mechanism that is still

35 incompletely understood. Using voltammetry in mouse mesencephalic brain slices, we

36 find that STD DA release has low capacity, is stable in response to electrical but not

37 optogenetic train pulses and shows a calcium sensitivity that is comparable to that of

38 axonal release. It is also strikingly more resilient compared to axonal release in a 6-

39 hydroxydopamine model of Parkinson's disease plasticity. We find that the molecular

40 mechanism of STD DA release differs from axonal release with regards to the

41 implication of synaptotagmin (Syt) calcium sensors. While individual constitutive knock-

42 out Syt4 and Syt7 is not sufficient to reduce STD DA release, removal of both isoforms

43 reduces this release by $\sim 50 \%$, leaving axonal release unimpaired. Our works unveils clear

44 differences in the mechanisms of STD and axonal DA release. 


\section{INTRODUCTION}

Dopamine (DA) neurons of the mesencephalon play a key role in motor control,

49 motivated behaviors and cognition ${ }^{1,2}$. DA neurons can release DA not only from axon

50 terminals by a classical exocytosis mechanism ${ }^{3}$, but also through their somatodendritic

51 (STD) compartment, as demonstrated by multiple approaches including in vivo

52 microdialysis, fast scan cyclic voltammetry (FSCV) and patch-clamp recordings of D2

53 receptor mediated currents in the ventral tegmental area (VTA) and substantia nigra pars

54 compacta $(\mathrm{SNc})^{4-7}$. These nuclei contain the cell body and dendrites of DA neurons, but

55 little if any DA-containing axon terminals ${ }^{5,8}$. Although there is limited direct evidence,

56 STD DA release is believed to be implicated in regulating the excitability of DA neurons

57 though activation of STD D2 autoreceptors ${ }^{9}$. It has also been suggested to regulate motor

58 behaviors $^{10,11}$, mainly by local activation of D1 receptors.

The molecular mechanism of STD DA release is still unclear. Reversal of the DA

transporter (DAT) has been proposed ${ }^{12}$, but this mechanism cannot account for the results

61 of studies that measured STD DA release in vitro and in vivo in the presence of DAT

62 blockers. These studies unequivocally show that blocking DAT leads to an increase in

63 extracellular DA, whether in evoked release $4,6,9,13,14$ or spontaneous release ${ }^{15-20}$. A

64 vesicular exocytotic-like mechanism has therefore been proposed, in agreement with the

65 fact that STD DA release is activity-dependent (TTX-sensitive) ${ }^{9,18,21}$, reserpine-

66 sensitive $e^{9,22,23}$, calcium-dependent ${ }^{9,13,18,20,22,24}$, and blocked by botulinum neurotoxins,

67 which disrupt SNARE-proteins ${ }^{18,25,26}$. Although large pools of DA-containing small clear

68 synaptic vesicles are not found in the dendrites of DA neurons, these dendrites contain

69 pleiomorphic vesicles that bear the vesicular monoamine transporter (VMAT2), 
70 suggesting that they could be sites of DA storage in dendrites ${ }^{27}$. Together, these findings

71 suggest that, although there may be some fundamental differences between the

72 mechanisms of terminal and STD DA release, both implicate a form of exocytosis.

73 Although STD DA release is calcium-dependent, conflicting results exist

74 regarding the calcium-sensitivity of STD DA release in comparison with axonal release.

75 Previous studies performed in guinea pig reported that STD DA release persists at

76 extracellular calcium concentrations as low as $0.5 \mathrm{mM}$, a concentration at which axonal

77 release is typically abrogated from most axon terminals ${ }^{13,18}$. In contrast, previous work

78 performed with mouse tissue and indirectly detecting STD DA release using the patch-

79 clamp technique and STD D2 receptor activation, reported that axonal and STD DA

80 release display a similar calcium-dependency ${ }^{9,24,28-31}$. Here, we reexamined this question

81 in mouse brain slices after optimizing direct detection of DA using FSCV.

83 motor behaviors during the progression of Parkinson's disease (PD). Compatible with the

84 dying-back hypothesis of PD suggesting that PD pathology starts at the axon terminal

85 level $^{32}$, previous work in rats measuring baseline STD DA release by microdialysis

86 suggested that this form of release, is preserved for longer periods of time compared to

87 axonal DA release following 6-OHDA lesions ${ }^{33}$. It is unclear if activity-dependent STD

88 release is similarly resilient. Here, we examined the impact of a striatal 6-

89 hydroxydopamine (6-OHDA) lesion on evoked STD DA release 1 day after the lesion,

90 where an early loss of axon terminals occurs, and 14 days after the lesion at a time where

91 soma and dendrites of DA neurons are severely impacted ${ }^{34}$. 
92 Finally, an important outstanding question is the identification of the molecular

93 mechanisms of STD DA release. Prior work has demonstrated that many proteins

94 involved in regulated exocytosis, such as the calcium sensor Syt1, are selectively targeted

95 to the axonal domain of neurons and not in dendrites ${ }^{3,19,35-37}$. Building on previous in

96 vitro work suggesting possible roles of Syt 4 and Syt $7^{19}$, in the present study we tested the

97 hypothesis that Syt4 and Syt7 play a key role in STD DA release in the intact brain by

98 quantifying STD DA release in Syt4, Syt7 and Syt4/7 double knockout (KO) mice. 


\section{Animals}

103 Male and female mice of 11-12 weeks were used in this study. For optogenetic

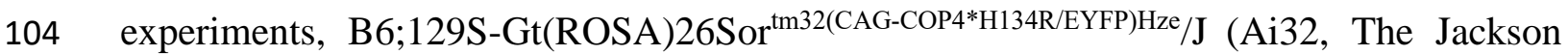
105 Laboratory, stock 012569, USA) homozygote mice expressing a floxed H134R variant of 106 the light-activated channelrhodopsin-2 were bred with homozygote B6.SJL107 Slc6a3 ${ }^{\text {tm1.1(cre)Bkmn} / J}$ (DAT ${ }^{\text {IREScre, }}$, The Jackson Laboratory, stock 006660, USA) 108 expressing the cre recombinase under control of the DAT promoter, allowing 109 channelrhodospin-2 to be expressed selectively in DA neurons. Heterozygote DAT ${ }^{\text {IREScre }}$ 110 mice were also used for experiments in which ChR2 was virally expressed. Constitutive 111 knock-out mice for Syt4 (129S6.129X1(B6)-Syt4 ${ }^{\text {tm1Hahe }} /$, The Jackson Laboratory, stock $112 \# 012400, \mathrm{USA})^{38}, \mathrm{Syt}^{39}$ and WT littermates were bred from heterozygous crosses or 113 crossed with each other to obtain double KO mice. Genotyping for Syt4 KO mice was 114 determined using specific primers to target the wild type Syt4 sequence (primers 115 Syt4WT-fwd and Syt4WT-rev) and the neomycin cassette within the mutated allele 116 (primers neo-fwd and Syt4WT-rev) - Syt4WT-fwd: 117 CACTTCCCTCACGTCAGAGGAG, - $\quad$ Syt4WT-rev: 118 GCAAGGAGAGCTCTTGGATGTG, - neo-fwd: AACCACACTGCTCGACATTGGG.

119 Genotyping for Syt7 KO mice was performed using specific primers to target the wild 120 type Syt7 sequence (Syt7WT-fwd: CATCCTCCACTGGCCATGAATG; - Syt7WT-rev: 121 GCTTCACCTTGGTCTCCAG) and the neomycin cassette within the mutated allele 122 (neo-fwd: CTTGGGTGGAGAGGCTATTC; neo-rev: 
123 AGgtgagAtgACAGGAGATC), as provided by Jackson. Genotyping for Syt7

124 mutation in combined Syt4/7 KO mice was determined using another set of specific

125 primers due to overlapping sequences within the neomycin cassette used in both the Syt4

126 and Syt7 mouse lines: - neo-fwd: CTTGGGTGGAGAGGCTATTC and Syt7WTexon4:

127 AGTGTCCAGGCTCCC. Experiments were performed blind with regards to animal

128 genotype, with the exception of Syt4 KO mice, because these $\mathrm{KO}$ mice could be easily

129 identified due to a neurodevelopmental alteration of the anterior commissure and corpus

130 callosum (Fig. S1). All procedures involving animals and their care were conducted in

131 accordance with the Guide to care and use of Experimental Animals of the Canadian

132 Council on Animal Care. The experimental protocols were approved by the animal ethics

133 committees of the Université de Montréal. Housing was at a constant temperature $\left(21^{\circ} \mathrm{C}\right)$

134 and humidity (60\%), under a fixed $12 \mathrm{~h}$ light/dark cycle, with food and water available ad

135 libitum.

\section{Stereotaxic injections}

6-7 week-old DAT ${ }^{\mathrm{IREScre}}$ mice were anesthetized with isoflurane (Aerrane; Baxter,

138 Deerfield, IL, USA) and fixed on a stereotaxic frame (Stoelting,Wood Dale, IL, USA). A

139 small hole was drilled in the exposed skull and a Hamilton syringe was used for the

140 injections. For optogenetic experiments, an adeno-associated virus (AAV5-EF1a-DIO-

141 hChR2(H134R)-EYFP, 4,2x10 $12 \mathrm{vg} / \mathrm{mL}$, UNC GTC Vector Core, USA) was injected

142 bilaterally at the following injection coordinates [AP (anterior-posterior; ML (medial-

143 lateral); DV (dorsal-ventral), from bregma], to infect neurons in the entire ventral

144 mesencephalon: AP -3.0 mm; ML +/- $1.0 \mathrm{~mm}$; DV $-4.5 \mathrm{~mm}$. Animals recovered in their

145 home cage and were closely monitored for 3 days. The animals were used one month 
146 after injection, allowing maximal expression of ChR2 in DA neurons. Success of the

147 injection was visually validated each time during the slicing of the brains by visualizing

148 the presence of the eYFP reporter. For 6-OHDA experiments, saline or 6-OHDA (5

$149 \mu \mathrm{g} / \mu \mathrm{L} ; 2 \mu \mathrm{L}$ in total, at a rate of $0.5 \mu \mathrm{L} / \mathrm{min}$, Sigma, Canada) were injected unilaterally in

150 the dorsal striatum: AP $+1.0 \mathrm{~mm}$; ML $+1.5 \mathrm{~mm}$; DV $-2.8 \mathrm{~mm}$. The brains were used for

151 FSCV experiments 1 or 14 days after the injection.

\section{Brain slice preparation and solutions}

Acute brain slices from 11-12-week-old male or female mice were used for the

154 FSCV recordings. When possible, matched pairs of WT and KO mice were used on each

155 experimental day. The animals were anesthetized with halothane, quickly decapitated and

156 the brain harvested. Next, the brain was submersed in ice-cold oxygenated artificial

157 cerebrospinal fluid (aCSF) containing (in $\mathrm{mM}$ ): $\mathrm{NaCl}(125), \mathrm{KCl}(2.5), \mathrm{KH}_{2} \mathrm{PO}_{4}(0.3)$,

$158 \mathrm{NaHCO}_{3}$ (26), glucose (10), $\mathrm{CaCl}_{2}$ (2.4), $\mathrm{MgSO}_{4}$ (1.3) and coronal VTA and/or striatal

159 brain slices of $300 \mu \mathrm{m}$ thickness were prepared with a VT1000S vibrating blade

160 microtome. Once sliced, the tissue was transferred to oxygenated aCSF at room

161 temperature and allowed to recover for at least $1 \mathrm{~h}$. For recordings, slices were placed in a

162 custom-made recording chamber superfused with aCSF at $1 \mathrm{ml} / \mathrm{min}$ and maintained at

$16332^{\circ} \mathrm{C}$ with a TC-324B single channel heater controller (Warner Instruments, USA). All

164 solutions were adjusted at $\mathrm{pH} 7.35-7.4,300 \mathrm{mOsm} / \mathrm{kg}$ and saturated with $95 \% \mathrm{O}_{2}-5 \%$

$165 \mathrm{CO}_{2}$ at least 30 min prior to each experiment.

\section{Fast scan cyclic voltammetry recordings}


168 diameter carbon-fiber electrode placed into the tissue $\sim 100 \mu \mathrm{m}$ below the surface. A

169 bipolar electrode (Plastics One, Roanoke, VA, USA) or an optical fiber connected to a

$170470 \mathrm{~nm}$ wavelength LED was placed $\sim 200 \mu \mathrm{m}$ away. Carbon-fiber electrodes were

171 fabricated as previously described ${ }^{40}$. Briefly, carbon fibers (Goodfellow Cambridge

172 Limited, UK) of $7 \mu \mathrm{m}$ in diameter were aspirated into ethanol-cleaned glass capillaries

173 (1.2 mm O.D., 0.68 mm I.D., 4 inches long; World Precision Instruments, FL, USA). The

174 glass capillaries were then pulled using a P-2000 micropipette puller (Sutter Instruments,

175 Novato, USA), dipped into $90^{\circ} \mathrm{C}$ epoxy for 30s (Epo-Tek 301, Epoxy Technology,

176 MASS, USA) and cleaned in hot acetone for $3 \mathrm{~s}$. The electrodes were heated at $100^{\circ} \mathrm{C}$ for

$17712 \mathrm{~h}$ and $150^{\circ} \mathrm{C}$ for 5 days. Electrodes were polished and filed with potassium acetate at

$1784 \mathrm{M}$ and potassium chloride at $150 \mathrm{mM}$. The protruding carbon fibers were cut using a

179 scalpel blade under direct visualization to a length allowing to obtain maximal basal 180 currents of 100 to $180 \mathrm{nA}$.

The electrodes were calibrated with $1 \mu \mathrm{M}$ DA in aCSF before and after each recorded slice and the mean of the current values obtained were used to determine the

183 amount of released DA. After use, electrodes were cleaned with isopropyl alcohol

184 (Bioshop, Canada). The potential of the carbon fiber electrode was scanned at a rate of $185300 \mathrm{~V} / \mathrm{s}$ according to a $10 \mathrm{~ms}$ triangular voltage wave (-400 to $1000 \mathrm{mV}$ vs $\mathrm{Ag} / \mathrm{AgCl})$ 186 with a $100 \mathrm{~ms}$ sampling interval, using a CV 203BU headstage preamplifier (Molecular 187 Devices) and a Axopatch 200B amplifier (Molecular Devices, USA). Data were acquired 188 using a Digidata 1440a analog to digital converter board (Molecular Devices, USA) 189 connected to a computer using Clampex (Molecular Devices, USA). Slices were left to 
190 stabilize for $20 \mathrm{~min}$ before any electrochemical recordings. After positioning of the

191 bipolar stimulation electrode or the optical probe and carbon fiber electrodes in the tissue,

192 single pulses $(400 \mu \mathrm{A}$ or $30 \mathrm{~mW}, 1 \mathrm{~ms}$, ) or pulses-train (30 pulses at $10 \mathrm{~Hz})$ were applied

193 to the tissue to trigger DA release. For evaluating the calcium dependency of axonal and

194 STD release, variations of calcium concentrations in the aCSF $(0,0.5$ and $2.4 \mathrm{mM})$ were

195 compensated by changing the concentration of $\mathrm{MgSO}_{4}$ to keep divalent cation levels 196 equivalent.

197 Immunohistochemistry

For Syt immunolabelling experiments, $40 \mu \mathrm{m}$ brain slices from animals perfused with 4\% paraformaldehyde (in PBS, pH-7.4) were cut with a cryostat (Leica CM 1800;

Leica Canada) and used for immunohistochemistry (IHC). Because selective and specific

201 Syt4, Syt7 and VMAT2 antibodies were all from the same host species (rabbit), a double

202 labeling protocol (Jackson ImmunoReseach) with monovalent Fab fragments was used.

203 After a PBS wash, the tissue was permeabilized, nonspecific binding sites blocked (goat

204 serum 5\%) and incubated overnight at room temperature with the first primary antibody

205 (rabbit anti-Syt1, anti-Syt4 or anti Syt7 from Synaptic Systems, Germany; 1:1000),

206 followed by $2 \mathrm{~h}$ with a first secondary antibody (rabbit Alexa Fluor-488-conjugated,

207 1:500, Invitrogen, Canada). A blocking step of antigenic sites from the first primary and

208 secondary antibody combination was performed thereafter by a $3 \mathrm{~h}$ incubation with

209 normal serum from the same species as the primary antibody, followed by a blocking

210 solution (goat block: PBS, Triton X100 0.3\%, bovine serum albumin 5\%) with $50 \mu \mathrm{g} / \mathrm{mL}$

211 of unconjugated monovalent Fab fragments against the host of the primary antibody,

212 overnight, at room temperature and under agitation. Slices were then washed, and a 
213 second labeling was performed with a second primary antibody (rabbit anti-VMAT2,

214 1:1000, gift of Dr. Gary Miller, Colombia University), and a second secondary antibody

215 (rabbit Alexa Fluor-546-conjugated, 1:500, Invitrogen). For each IHC staining, a control

216 group was included, with the full protocol except for omission of the second primary

217 antibody. A classical immunostaining protocol was used for the knockout validation of

218 Syt4 and Syt7 antibodies (Fig. S2), using mouse anti-tyrosine hydroxylase (Millipore

219 Sigma; 1:1000) and rabbit anti-Syt4 or anti-Syt7 primary antibodies (Synaptic Systems;

220 1:1000) subsequently detected using Alexa Fluor-488-conjugated and Alexa Fluor-546-

221 conjugated secondary antibodies (Invitrogen; 1:500).

\section{Confocal Imaging}

223 Images were acquired using an Olympus Fluoview FV1000 point-scanning confocal 224 microscope (Olympus, Canada) with a 60x oil-immersion objective (NA 1.35). Images 225 acquired using $488 \mathrm{~nm}$ and $546 \mathrm{~nm}$ laser excitation were scanned sequentially to prevent 226 non-specific bleed-through signal. All image analysis was performed using ImageJ 227 (National Institutes of Health) software.

\section{Reverse Transcriptase-quantitative PCR}

229 We used RT-qPCR to quantify the amount of mRNA encoding Syt1, 4, 5, 7 and 11 in 230 brain tissue from $\mathrm{P} 70 \mathrm{Syt}^{+/+}$and $\mathrm{Syt}^{-/-}$mice and $\mathrm{P} 70 \mathrm{Syt}^{+/+}$and $\mathrm{Syt}^{-/-}$mice. Adult 231 whole brains were harvested and homogenized in Trizol solution, then RNA extraction 232 was performed using RNAeasy Mini Kit (Quiagen, Canada) according to the 233 manufacturer's instructions. The concentration and purity of the RNA from DA neurons 234 were determined using a NanoDrop 1000 (Thermo Scientific, Waltham, MA USA). Total 235 purified RNA (40 ng) was reverse-transcribed in a total of $20 \mu$ l including $1 \mu \mathrm{l}$ of dNTP, 
$2361 \mu \mathrm{l}$ of random hexamer, $4 \mu \mathrm{l}$ of $5 \mathrm{X}$ buffer $5 \mathrm{X}, 2 \mu \mathrm{l}$ of dithiothreitol (DTT), $1 \mu \mathrm{l}$ of

237 RNAse-Out and $1 \mu \mathrm{l}$ of the Moloney Murine Leukemia Virus reverse transcriptase

238 enzyme (MML-V, Invitrogen). Quantitative PCR was carried out in a total of $15 \mu 1$

239 consisting of $3 \mu 1 \mathrm{cDNA}, 7.5 \mu 1 \mathrm{SYBER}$ green PCR master mix (Quanta Biosciences,

$240 \mathrm{USA}$ ), $10 \mu \mathrm{M}$ of each primer, completed up to $15 \mu \mathrm{l}$ with RNA-free water. qPCR was

241 performed on a Light Cycler 96 machine (Roche, Canada) using the following procedure:

$24210 \mathrm{~min}$ at $95^{\circ} \mathrm{C} ; 40$ cycles of $30 \mathrm{~s}$ at $95^{\circ} \mathrm{C}, 40 \mathrm{~s}$ at $57^{\circ} \mathrm{C}$ and $40 \mathrm{~s}$ at $72^{\circ} \mathrm{C} ; 1$ cycle of $15 \mathrm{~s}$ at

$24395^{\circ} \mathrm{C}, 15 \mathrm{~s}$ at $55^{\circ} \mathrm{c}$ and $15 \mathrm{~s}$ at $95^{\circ} \mathrm{C}$. Results were analysed with Light Cycler 96 software

244 and Excel. The efficiency of the reaction $\left(E=10^{(-1 / \text { slope })}-1\right)$ was calculated from the slope

245 of the linear relationship between the $\log$ values of the RNA quantity and the cycle

246 number $(\mathrm{Ct})$ in a standard curve. Calculation of relative mRNA levels was performed by

247 using the $2^{\wedge}(-\mathrm{DDCt})$ formula ${ }^{41}$, where the $\mathrm{Ct}$ value of the mRNA level for Syt1, 4, 5, 7

248 and 11 was normalized to the $\mathrm{Ct}$ value of GAPDH in the same sample. Ct values used

249 were the mean of duplicate repeats. Melt-curves of tissue homogenate indicated specific

250 products after Syt1, 4, 5, 7 and 11 qPCR mRNA amplification, attesting of the adequate

251 quality of the primers chosen (not shown). Primers were designed with the Primers 3 and

252 Vector NTI software and were synthetized by Alpha DNA (Montreal, QC). Primers for

253 qPCR were as follows: Syt1: 5' GTGGCAAGACACTGGTGAT 3' and 5'

254 CtCAGgaCtCtgGagatcG 3' ; Syt4: 5' CACTTCCCtCACGTCAGAGgag 3'

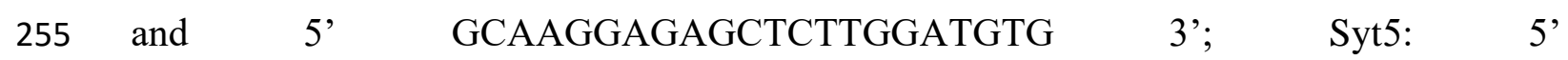

256 GTCCCATACGTGCAACTAGG 3' and 5' AACGGAGAGAGAAGCAGATG 3'; Syt7:

257 5' CCAGACGCCACACGA 3' and 5' CCTTCCAGAAGGTCT 3'; Syt11: 5'

258 CTtGtatgGCGGGGtCTtGT 3' and 5' AtACGCCCCAGCTTTGATGA 3' and 
259 GAPDH: 5' GGAGGAAACCTGCCAAGTATGA $\quad 3^{\prime} \quad$ and $\quad 5^{\prime}$

260 TGAAGTCGCAGGAGACAACC 3'. Primers were tested by comparing primers

261 sequences to the nucleotide sequence database in GenBank using BLAST

262 (www.ncbi.nlm.nih.gov/BLAST/).

263

\section{Statistics}

265 Data are presented as mean +/- SEM. The level of statistical significance was established 266 at $\mathrm{p}<0.05$ in one-way ANOVAs with appropriate post-hoc tests and two-tailed tests,

267 performed with Prism 8 software (GraphPad, $* \mathrm{p}<0.05, * * \mathrm{p}<0.01, * * * \mathrm{p}<0.001, \# \mathrm{p}<$ $2680.0001)$. 


\section{RESULTS}

\section{D2 autoreceptors and DAT limit the extent of somatodendritic dopamine release in}

273 mouse VTA slices

The difficulty to reliably detect STD DA release in mouse rodent slices has greatly slowed progress in better understanding the mechanisms and roles of this form of DA release. We therefore first aimed to optimize its detection in mouse VTA slices by

277 comparing different modes of stimulation and physiological parameters that may limit its 278 extent.

Previous studies performed in brain slices or in vivo typically triggered STD DA

280 release using extracellular electrical stimulation ${ }^{42-44}$. A downside of this approach is that

281 it non-selectively depolarizes local afferent terminals and the cell bodies of local GABA

282 and glutamate neurons in addition to DA neurons. In recent years, optical stimulation 283 using channelrhodopsin-2 (ChR2) or other opsin variants has increasingly been used to 284 obtain more selective activation of DA neuron axons ${ }^{45}$. However, to this date, this 285 approach has not been used to selectively trigger STD DA release in FSCV experiments. 286 We first evaluated whether optogenetic stimulation of DA neurons might be more 287 effective to trigger STD DA release or produce more stable release (Fig. 1A, 1B). stimulation. Recordings were performed in the VTA of DAT ${ }^{\text {IREScre }} / A i 32$ mice, in which

290 ChR2 is conditionally expressed in all DA neurons, and in DAT ${ }^{\text {IREScre }}$ heterozygote mice 291 injected in the VTA with a floxed hChR2-EYFP AAV construct. Neither stimulation 
292 conditions, either in normal ACSF or in the presence of DAT (nomifensine, $5 \mu \mathrm{M}$ ) and

293 D2 receptor blockade (sulpiride, $5 \mu \mathrm{M}$ ) yielded detectable evoked elevations of

294 extracellular DA (Fig. 1C, 1D). However, the use of pulse trains (30 pulses at $10 \mathrm{~Hz})$ in

295 the presence of nomifensine and sulpiride allowed reliable detection of STD DA release

296 in VTA slices, both for electrical stimulation (average peak DA levels of $340 \mathrm{nM}+/-28$

$297 \mathrm{nM}$ in DAT ${ }^{\mathrm{IREScre}} / \mathrm{Ai} 32$ mice $[\mathrm{n}=15]$ and $333 \mathrm{nM}+/-32 \mathrm{nM}$ in DAT ${ }^{\text {IREScre }}$ mice infected

298 with ChR2 AAV [n = 10]) and for optical stimulation (average peak DA levels at $187 \mathrm{nM}$

$299+/-17 \mathrm{nM}$ in DAT ${ }^{\mathrm{IREScre}} / \mathrm{Ai} 32$ mice $[\mathrm{n}=15]$ and $220 \mathrm{nM}+/-37 \mathrm{nM}$ in DAT ${ }^{\mathrm{IREScre}}$ mice

300 infected with ChR2 AAV [ $n=10])$. Although peak levels of activity-dependent STD DA

301 release in the two strains of mice tended to be higher with electrical compared to optical

302 stimulation, the difference between the two modes of stimulation was not significantly

303 different (Fig. 1C, 1D, right bar graphs).

304 Reuptake through the DAT and the D2 autoreceptor are two well-known

305 regulators of extracellular DA levels and DA release ${ }^{46-48}$. We next examined the effect of

306 DAT and D2 receptor blockade individually to determine whether a combined block of

307 reuptake and autoreceptor function was required to reliably detect STD DA release in

308 response to electrical train stimulation. Each recording was performed after 15 min of

309 nomifensine or sulpiride or a combination of the two. Baseline levels of evoked DA in

310 the absence of antagonist were very small, but still reliably detectable (49 $\mathrm{nM}+/-6 \mathrm{nM})$.

311 Blockade of DAT or D2 receptors individually, caused a significant increase in the

312 maximal amplitude of evoked STD DA release in the VTA $(+296 \%+/-42 \%$ for

313 nomifensine alone $[\mathrm{n}=6],+210 \%+/-28 \%$ for sulpiride alone $[\mathrm{n}=6])$, while a

314 combination of the two drugs caused a cumulative increase of $500 \%+/-51 \%$ [n $=12$ ], 
315 thus demonstrating that the two manipulations were mostly additive and that a combined

316 blockade of both membrane proteins allowed to maximally increase the detected signal.

321 slices, repeated stimuli were found to cause stimulation-dependent attenuation ${ }^{5}$. This

322 represents a major limiting factor to further examine the mechanisms of this form of

323 release. Using optical train stimulation in the presence of nomifensine and sulpiride, we

324 therefore evaluated the stability of STD DA release in response to a series of 7

325 consecutive stimuli with an interstimulus interval of $5 \mathrm{~min}$. STD DA overflow evoked by

326 optical stimulation showed a robust and progressive decrease in peak amplitude in

327 response to repeated stimuli (Fig. 2A). By the end of the stimulation protocol, evoked

328 STD DA release decreased by approximately $50 \%$ in DAT IREScre $^{\text {Ai3 } 32 ~ m i c e ~ a n d ~ b y ~}$

329 approximately $40 \%$ in virally transduced DAT ${ }^{\text {IREScre }}$ mice. Compatible with the

330 possibility that this decrement was due to rundown of releasable pools of DA, a 20 min

331 delay before a final stimulation revealed a clear partial recovery. Strikingly, electrical

332 stimulation failed to cause a similarly extensive rundown of STD DA, with only a

333 modest, non-significant decrease of less than $20 \%$ detected by the last of 7 stimuli (Fig.

334 2B). Although speculative, this lack of rundown in response to electrical stimulation

335 could be due to the recruitment of afferent fibers that secrete neuromodulators able to

336 maintain vesicular DA stores for longer periods of time. Due to this favorable 
337 characteristic of electrical stimulation on the stability of STD DA release, all further

338 experiments were performed with this mode of stimulation.

\section{DA release in the VTA and striatum exhibit similar calcium dependency}

As we aimed to examine the role of Syt calcium sensors in STD DA release and in

342 the face of conflicting previous results regarding the extent to which STD DA release

343 depends upon extracellular calcium levels in comparison with axonal release ${ }^{24,49}$, we next

344 evaluated the release of DA at $0,0.5$ and $2.4 \mathrm{mM}$ of extracellular calcium in both the

345 dorsal striatum (axonal release) and VTA (Fig. 3A). As expected, based on previous

346 results $^{13}$, no release was detected in the striatum at $0 \mathrm{mM}$ and $0.5 \mathrm{mM}$ calcium, neither in

347 response to single pulses or to trains $(n=13$ slices $/ 7$ mice $)($ Fig. 3B $)$.

348 In the VTA, STD DA release, here again triggered in the presence of 349 nomifensine/sulpiride $(5 \mu \mathrm{M})$, was also undetectable at $0 \mathrm{mM}$ extracellular calcium $(\mathrm{n}=$ 35013 slices/7 animals), but readily detectable at $0.5 \mathrm{mM}(\mathrm{n}=16$ slices $/ 10$ mice $)$ (Fig. $3 \mathrm{C})$, 351 as previously described in the guinea pig $^{49}$. Evoked STD DA release at this concentration 352 of calcium was however only $19 \%$ of the signal detected at $2.4 \mathrm{mM}$ calcium $(76 \mathrm{nM}+/-$ $35310 \mathrm{nM}$, compared to $388 \mathrm{nM}+/-39 \mathrm{nM}$ ) (Fig. 3C, 3D). Recordings performed in striatal 354 slices in the presence of nomifensine and sulpiride similarly revealed detectable DA 355 release at $0.5 \mathrm{mM}$ calcium (Fig. 3B) $(1.1 \mu \mathrm{M}+/-0.17 \mu \mathrm{M}, \mathrm{n}=13$ slices $/ 7$ mice). This 356 represents $16 \%$ of the DA signal detected at $2.4 \mathrm{mM}$ calcium $(7 \mu \mathrm{M}+/-0.87 \mu \mathrm{M})$ (Fig. 357 3B, 3D). Therefore, under the same experimental conditions, with no influence of DA 
358 uptake and D2 autoreceptor activation, evoked STD and axonal DA release show a

359 similar calcium dependency. All further experiments were performed at $2.4 \mathrm{mM}$ calcium.

\section{STD DA release is more resilient than axonal release in a Parkinson's disease model}

The differential properties of axonal and STD DA release might in part be

362 involved in explaining the differential impairment of these two forms of release in PD.

363 We therefore examined the resilience of STD DA release in the intrastriatal 6-

364 hydroxydopamine (6-OHDA) model, often used to study adaptation of the DA system in

365 the context of PD progression. Interestingly, previous work performed in the rat showed

366 that extracellular DA levels in the SNc, as determined by in vivo microdialysis, are not

367 altered several weeks after a 6-OHDA lesion in the medial forebrain bundle (MFB),

368 while a major loss of DA content was seen in the striatum ${ }^{33}$. We used a protocol adapted

369 from Stott and Barker ${ }^{34}$, who observed that within hours, intra-striatal 6-OHDA (5

$370 \mu \mathrm{g} / \mu \mathrm{L}, 2 \mu \mathrm{L})$ can impact $\mathrm{TH}+$ fibers in the striatum, while the impact at the STD

371 compartment is delayed for several days post-surgery, even if approximately 50\% of DA

372 neurons degenerate by 12 days. We unilaterally injected saline or 6-OHDA in the dorsal

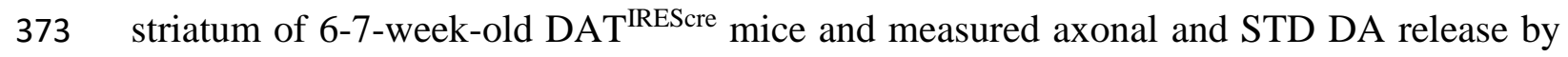

374 FSCV 24h or 14 days after the injections (Fig.4A).

We found at 1-day post-injection a $>99 \%$ decrease of electrically evoked DA

376 overflow in the dorsal striatum, confirming the robust and acute effect of 6-OHDA on

377 DA axonal fibers $[\mathrm{n}=12$ slices/6 mice] (Fig.4B). This abolition of axonal DA release

378 was also maintained after 14 days [n= 10 slices/5 mice]. Intriguingly, a small decrease of

379 evoked axonal DA overflow was also detected in the contralateral striatum at day-1 (1.1

$380 \mu \mathrm{M}+/-0.06 \mu \mathrm{M}$ vs $1.39 \mu \mathrm{M}+/-0.08 \mu \mathrm{M}$ at 14 days), something that was not observed in 
381 saline-injected control mice $(1.3 \mu \mathrm{M}+/-0.09 \mu \mathrm{M}$ vs $1.28 \mu \mathrm{M}+/-0.07 \mu \mathrm{M}$ at 14 days).

382 As expected, there was otherwise no impact of the injection itself on DA overflow, has

383 seen in all saline treated animals $[\mathrm{n}=12$ slices/ 6 mice for each time point $]$ (Fig.4C and

384 E).

In a sharp contrast, 1 day after 6-OHDA, STD DA release at the level of the SNc

386 was not reduced, but rather significantly higher in the 6-OHDA lesioned hemisphere

$387(0.27 \mu \mathrm{M}+/-0.03 \mu \mathrm{M},[\mathrm{n}=13$ slices/6 mice $])$ compared to the contralateral side $388(0.18 \mu \mathrm{M}+/-0.03)$ (Fig.4D). At 14 days, a stage at which it is expected that 389 neurodegeneration has reached the STD compartment and approximately half of SNc DA 390 neurons have degenerated ${ }^{34}$, only a tendency of a decrease of DA release in the lesioned$391 \mathrm{SNc}(0.12 \mu \mathrm{M}+/-0.015$, [n = 10 slices/5 mice]) was observed compared to the 392 contralateral side $(0.17 \mu \mathrm{M} 0.034 \mu \mathrm{M})$, a change that was not significant. There were no 393 significant changes in STD DA release in the VTA region at 1 or 14 days after 6-OHDA. 394 Altogether these data indicate that while axonal release is very sensitive to the toxic 395 effects of a single 6-OHDA injection, STD release is strikingly more resilient.

\section{Dopamine neurons express the calcium-sensors synaptotagmin 1, 4 and 7}

398 were previously suggested to be critical for STD DA release based on in vitro 399 experiments ${ }^{19}$, we next evaluated the presence and subcellular localization of these Syt 400 isoforms in DA neurons in vivo in the mouse brain. 
403 compartments containing the vesicular monoamine transporter VMAT2. Due to the

404 impossibility to obtain suitable VMAT2 and Syt antibodies produced in different species,

405 we took advantage of a double labelling protocol allowing the use of two primary

406 antibodies from the same species (rabbit) (Fig. 5A). The approach was validated by the

407 observation that in control experiments in which the second primary antibody was

408 omitted, no signal was detected for the second antigen, demonstrating that the second

409 secondary antibody was unable to bind to the first primary antibody after the blocking

410 step. Immunoreactivity for Syt4 showed a clear somatic localization in DA neurons, with

411 a notable overlap with VMAT2 (Fig. 5B), with little if any signal in terminals in the

412 striatum. Confirming the specificity of the antibody, signal was absent from Syt4 KO DA

413 neurons (Fig. S2A). Syt7 immunoreactivity was found in both the STD region of DA

414 neurons as well as in their terminal region in the striatum (Fig. 5D). Syt7

415 immunoreactivity was strongly reduced in Syt7 KO tissue, although some background

416 signal was still detectable (Fig. S2B), suggesting sub-optimal specificity. Finally, Syt1

417 was undetectable in the soma and dendrites of DA neurons, but highly expressed in the

418 terminals in the striatum, as expected (Fig. 5D). 
426 wild-type, heterozygous and $\mathrm{KO}$ littermates were compared, and recordings were

427 performed for each mouse in the dorsal striatum, the ventral striatum (nucleus accumbens

428 core and shell) and the VTA. These experiments revealed that axonal and STD DA

429 release in the VTA were not significantly reduced in Syt4 or Syt7 KO mice (Fig. 6A,

430 6B). The absence of effect of Syt4 or Syt7 KO on STD DA release could be due to the

431 ability of one isoform to compensate for the other in the STD compartment, with or

432 without compensatory upregulation of the expression of the other isoform. Using qRT

433 PCR in whole brain homogenates, we found that the total levels of Syt7 mRNA in Syt4

$434 \mathrm{KO}$ mice were unchanged, as were the levels of Syt4 mRNA in Syt7 KO mice (Fig. S2B, 435 S2D).

To examine if functional compensation can explain the lack of change in STD DA

437 release in the single $\mathrm{KO}$ mice, we next crossed these two mouse lines to generate a 438 double Syt4 and Syt7 KO. As controls, Syt4 ${ }^{-/-} ; \mathrm{Syt}^{+/-}$and $\mathrm{Syt}^{-/-} ; \mathrm{Syt}^{+/-}$animals were

439 also used for the FSCV recordings. Once again, no significant differences were found in

440 the dorsal and ventral striatum (Fig. 6C). The amount of DA released in the VTA of Syt4-

$441{ }^{/-} ; \mathrm{Syt}^{+/-}(0.334 \mu \mathrm{M}+/-0.04 \mu \mathrm{M} ; \mathrm{n}=6$ mice $)$ was similar to controls from the Syt 4 and

442 Syt7 individual KO mouse lines (respectively $0.341 \mu \mathrm{M}+/-0.044 \mu \mathrm{M} ; \mathrm{n}=8$ mice and

$4430.32 \mu \mathrm{M}+/-0.046 \mu \mathrm{M} ; \mathrm{n}=5$ mice). However, in $\mathrm{Syt}_{4}{ }^{-/-} ; \mathrm{Syt}^{-/-}$animals, we found a

444 robust and significant $\approx 50 \%$ decrease of STD DA release $(0.162 \mu \mathrm{M}+/-0.014 \mu \mathrm{M} ; \mathrm{n}=9$

445 mice). Interestingly, the $\mathrm{Syt}^{-/-} ; \mathrm{Syt}^{+/-}$animals also showed a systematic decrease of

446 STD DA release of about $\sim 50 \%(0.175 \mu \mathrm{M}+/-0.016 \mu \mathrm{M} ; \mathrm{n}=8$ mice $)$. Together these

447 results argue that both Syt4 and Syt7 isoforms contribute to STD DA release, with

448 functional compensation of one isoform by the other. These data also suggest a more 
449 critical role of Syt7 compared to Syt4 because the presence of only one Syt7 allele is

450 sufficient to support STD DA release in the absence of Syt4.

\section{Discussion}

\section{Characteristics of STD DA release}

In the present study, we performed the first characterization of optically evoked

455 STD DA release in the mouse mesencephalon using a combination of optogenetics and

456 FSCV and compared its characteristics to release evoked by electrical stimulation. As

457 previously reported by others, we found that the absolute levels of evoked DA overflow

458 detected in this region were low compared to levels detected in the terminal region in the

459 striatum. Furthermore, we found that a robust STD DA release signal could only be

460 detected using pulse-train stimulation (Fig.1). Blocking DA reuptake and D2

461 autoreceptor function using nomifensine and sulpiride caused a 5-fold increase in peak

462 signal amplitude, thus making detection of this signal straightforward and reproducible.

464 with a 5 min interval produces a strong rundown of STD DA release, whereas no such

465 attenuation was seen with electrical stimulation (Fig.2). This finding is compatible with

466 previous results reporting a similar rundown of optically-evoked axonal DA release in the

467 striatum ${ }^{45}$. It is therefore conceivable that the decrease observed with optical stimulation

468 results from a low reserve capacity of STD DA release due to limited vesicular reserve

469 pools in the soma and dendrites of DA neurons. It is equally possible that in response to

470 electrical stimulation, a similar decrement is not observed because this form of 
471 stimulation recruits neuromodulatory mechanisms that result from activation of afferent

472 terminals releasing 5-HT, NE, acetylcholine, glutamate, GABA or neuropeptides onto

473 DA neurons ${ }^{45,50}$. Further experiments will be required to test this hypothesis.

474 Our experiments comparing the impact of changes in extracellular calcium levels

475 of STD and axonal DA release argue for the existence of a similar calcium dependency

476 for both forms of release (Fig. 3). These findings are compatible with previous results

477 obtained in mice, which were performed using patch-clamp recordings and the

478 measurement of STD D2 receptor ${ }^{24}$. It is possible that a different conclusion was reached

479 in guinea pig brain slices because some aspect of the STD DA release mechanism is

480 different in that species $^{13}$. Another possibility is that a small component of axonal DA

481 release is also included in the signal detected in the VTA. This possibility has been raised

482 previously $^{49}$, but the available anatomical data actually suggests that DA containing

483 axonal varicosities are extremely scarce in the $\mathrm{VTA}^{51,52}$, except in the context of

484 compensatory axonal sprouting associated with partial lesions ${ }^{53}$. It would nonetheless be

485 useful to revisit this question with additional anatomical work in the future to provide 486 more quantitative data.

\section{Implications of STD DA release in PD}

The differential resilience of STD DA release in comparison to that of terminal

489 DA release is of particular interest because a major hypothesis of PD progression

490 proposes that loss of function begins at the axon terminal level, only later progressing to

491 loss of cell bodies (i.e. the dying back hypothesis of PD) ${ }^{32,54}$. In this context, it may be

492 hypothesised that at early stages of PD, STD DA release may still be functional and

493 contribute to partial maintenance of DA-dependent regulatory mechanisms in the ventral 
494 midbrain. Of relevance, it has been proposed that STD DA release contributes, along with

495 axonal DA release to motor behaviors ${ }^{55,56,10,57}$. Although a major focus of PD research

496 has been on restoring DA release in the striatum with L-DOPA treatment ${ }^{58}$ or with

497 transplantation of mesencephalic tissue ${ }^{59}$, the possible contribution of STD DA release to

498 functional adaptation or perturbation of basal ganglia circuit function in PD has received

499 little attention until now. Here we thus evaluated how STD DA release changes over time

500 after intra-striatal 6-OHDA, used to model PD axonal dying-back. We observed that

501 axonal release is very sensitive to the neurotoxic effect of 6-OHDA, as previously

502 known. In comparison, we found that STD DA release persists with no major decrement

503 for up to 14 days after the lesion, thus reflecting its high level of resilience. This

504 observation is in agreement with previous data from microdialysis experiments

505 measuring basal DA levels in the mesencephalon of 6-OHDA-lesioned rats $^{33}$. Our finding

506 of an increase in STD DA release in the SNc at 1 day after the lesion further suggests that

507 at early stages of PD pathophysiology, the loss of axonal DA signaling in the dorsal

508 striatum could constitute a signal for SNc neurons to upregulate their STD DA release as

509 a possible compensatory mechanism to sustain normal functions. Although this

510 hypothesis is speculative and will require further experiments to clarify the full time-

511 course and the mechanisms involved, these findings raise interest in further investigating

512 STD DA release and its plasticity in more disease-relevant PD models. It would also be

513 of interest to disentangle the possible contributions of STD and axonal DA release in the

514 VTA after partial lesions because of the possible appearance of aberrant compensatory

515 axonal fibers in the mesencephalon in such models ${ }^{53}$.

\section{Contribution of Syt4 and Syt7 to STD DA release}


Finally, we examined the contribution of the synaptotagmin isoforms Syt4 and

518 Syt7 to STD DA release. Acute downregulation of both isoforms has previously been

519 shown in vitro to severely reduce STD DA release, with no similar effect of Syt1

520 downregulation ${ }^{19}$. Although our present immunostaining results provide further support

521 for the presence of these proteins in the STD compartment of DA neurons, we failed to

522 detect any significant decrease in evoked STD DA release in VTA slices prepared from

523 individual constitutive Syt4 or Syt7 KO mice. It is possible that contrarily to acute

524 downregulation with siRNAs, constitutive gene deletion may lead to homeostatic

525 compensation leading to elevated levels of Syt4 in Syt7 KO mice and vice versa. It is also

526 possible that in vitro models lack homeostatic compensatory mechanisms that are

527 recruited in vivo. Our experiments quantifying Syt4 and Syt7 total mRNA levels failed to

528 provide support for such a compensation. Another possibility is therefore that Syt4 and

529 Syt7 play similar roles in supporting STD DA release and that one can compensate for

530 absence of the other in the context of constitutive gene deletion. The robust decrease in

531 activity-dependent STD DA release in Syt4/Syt7 double KO mice supports this

532 interpretation. In Syt4 ${ }^{-/-} ; \mathrm{Syt}^{-/-}$mice or $\mathrm{Syt}^{-/-} ; \mathrm{Syt}^{+/-}$mice, we observed a two-fold

533 decrease of STD DA release. This decrease was surprisingly not found in $\mathrm{Syt}^{-{ }^{--}} ; \mathrm{Syt}^{+/-}$

534 mice, strongly suggesting that Syt7 plays a particularly important role and that a single

535 allele of Syt7 is sufficient to sustain STD DA release in the absence of Syt4.

536 Considering that in the absence of both Syt4 and Syt7, approximately half of total

537 STD DA release levels remain, we hypothesise that other calcium sensors are also

538 involved. One possible candidate is Syt11. This isoform is interesting because like Syt4,

539 it has been reported to be present in the STD compartment of neurons ${ }^{60}$. Like Syt4, it also 
540 contains a natural mutation in one of its $\mathrm{C} 2$ calcium-binding domain, compatible with a

541 regulatory role in exocytosis rather than a classical calcium-sensing role ${ }^{61}$. Finally, like

542 Syt4, Syt 11 is a risk locus for $\mathrm{PD}^{62,63}$, and is a substrate of the E3 ubiquitin ligase parkin,

543 linked to early-onset familial forms of PD. Intriguingly, Syt11 overexpression in the SNc

544 has been reported to cause a decrease of DA release in the striatum ${ }^{64}$. Finally, the main

545 synaptotagmin isoform Syt1 might also be of interest, as it was recently demonstrated as

546 the main calcium sensor for fast striatal DA release $\mathrm{e}^{37}$. We have not found strong evidence

547 for localization of Syt1 in the STD domain of DA neurons, but further examination of

548 this possibility with higher resolution techniques would be warranted. A broader

549 evaluation of the contribution of other synaptic and exocytosis proteins in STD DA

550 release would also be useful. Interestingly, evoked STD DA release measured as D2-

551 IPSCs was recently reported to be abolished in mice with conditional deletion of the

552 active zone protein RIM, while spontaneous release remained intact ${ }^{65}$. However, the

553 subcellular localization of RIM in the STD compartment of DA neurons is currently

554 undetermined.

555 Together our work provides a new perspective on the mechanisms of STD DA

556 release and renews the interest in better understanding its roles in normal brain function

557 and in diseases such as PD. 


\section{FIGURE LEGENDS}

559

\section{Figure 1: Optogenetic and electrical stimulation trigger comparable levels of} somatodendritic dopamine release in mouse VTA slices. (A) Animal models used for optogenetic experiments. We either used a mouse line expressing a floxed version of light-activated channelrhodopsin (ChR2) crossed with a DA-specific Cre driver line (DAT IREScre) or performed stereotaxic injections of AAV5-EF1a-DIO-hChR2(H134R)eYFP virus in the VTA of DAT IREScre mice to selectively express ChR2 in DA neurons. (B) Fast Scan Cyclic Voltammetry was used to monitor DA levels. A voltage ramp of -400 to $1000 \mathrm{mV}$ vs Ag/AgCl at $300 \mathrm{~V} / \mathrm{s}$ was used, with a $100 \mathrm{~ms}$ sampling interval. Recordings were made in coronal slices containing the VTA and DA release was triggered by either optical stimulation with a $470 \mathrm{~nm}$ blue light LED or with a bipolar stimulating electrode.

(C) Top, representative traces of responses obtained in the VTA with 1 pulse (1ms) of blue light («single pulse») or a pulse-train of stimulation (30 pulses of $1 \mathrm{~ms}$ at $10 \mathrm{~Hz}$ ), in the presence of normal ACSF or ACSF + a DAT blocker (nomifensine, $5 \mu M$ ) and an antagonist of D2 autoreceptors (sulpiride, $5 \mu M$ ). Bottom, voltammograms of the representative traces. (D) Top, representative traces of responses obtained in the dorsal striatum with 1 electrical pulse $(1 \mathrm{~ms}, 400 \mu \mathrm{A})$ or a pulse-train (30 electrical pulses of 1 ms at $10 \mathrm{~Hz}, 400 \mu \mathrm{A}$ ), in the presence of ACSF or ACSF $+5 \mu M$ nomifensine/sulpiride. Bottom, voltammograms of the representative traces. (E) Effect of nomifensine/sulpiride on STD DA release measured by pulse-train electrical stimulation. 
580 Figure 2: Optogenetic stimulation reveals strong use-dependent attenuation of

581 evoked STD DA release in the VTA. (A) Average [DA]o peaks normalized to the first

582 stimulation in the VTA of AI32 and injected DAT IREScre mice evoked by optical stimulation

583 trains (30 pulses of $1 \mathrm{~ms}$ at $10 \mathrm{~Hz}, 470 \mathrm{~nm}$ blue light LED). (B) Same with pulse-train

584 electrical stimulation (30 pulses of $1 \mathrm{~ms}$ at $10 \mathrm{~Hz}, 400 \mu \mathrm{A})$. Each record was obtained in

$585 a C S F+5 \mu M$ nomifensine/sulpiride with 1 recording site per slice; inter-stimulus

586 interval between stims 1-7 = 5 min, inter-stimulus interval between stim 7 and $8=20$

587 min. Error bars represent +/- S.E.M. and the statistical analysis was carried out by a 1-

588 way ANOVA followed by a Dunnett test (ns, non-significant; *, $p<0.05$; **, $p<0.01$;

$589 * * *, p<0.001 ; * * * *, p<0.0001)$. The bold number represents the number of slices

590 recorded/number of animals used.

591 Figure 3: Somatodendritic and axonal dopamine release exhibit a similar calcium

592 dependency. (A) Protocol used for FSCV recordings. (B) Schematic representation of a

593 striatal slice and average of [DA] peaks obtained with single or pulse-train stimulations

594 at 0, 0.5 and $2.4 \mathrm{mM}$ of extracellular calcium in the aCSF, with or without addition of 5

$595 \mu M$ of nomifensine/sulpiride. (C) Schematic representation of a VTA slice and average

596 [DA] peaks obtained with pulse-train stimulations at 0, 0.5 and $2.4 \mathrm{mM}$ of extracellular

597 calcium in the aCSF containing $5 \mu M$ of nomifensine/sulpiride. (D) Average [DA]o peaks

598 normalized to $2.4 \mathrm{mM}$ of calcium obtained in the VTA and dorsal striatum (dStr) with

599 pulse-train stimulation and aCSF containing nomifensine/sulpiride. Representative traces

600 and voltammograms are shown on the right. Error bars represent +/- S.E.M. The

601 statistical analysis was carried out by a 1-way ANOVA followed by a Dunnett test (ns,

602

non-significant; ***, $p<0.001 ; \#, p<0.0001)$. 
603 Figure 4: STD DA release is more resilient than axonal release in a model of

\section{Parkinson's disease related axonal dying-back.}

605 (A) Protocol used for 6-OHDA experiments. Single doses of $2 \mu \mathrm{l}$ at $5 \mu \mathrm{g} / \mu \mathrm{l}(10 \mu \mathrm{g})$ of 6606 OHDA were injected in 6-7 weeks old mice in the dorsal striatum. FSCV experiments 607 were conducted 1 day (1D) or 14 days (14D) after the injections and DA overflow was 608 measured in striatal and mesencephalic slices. (B and $\boldsymbol{C})$ Average [DA]o peaks ( $\mu M)$ 609 obtained in the dorsal striatum of 6-OHDA treated $(B)$ and saline-treated $(C)$ mice. $(\boldsymbol{D}$ 610 and $\boldsymbol{E})$ Average [DA]o peaks $(\mu M)$ obtained in the mesencephalon of 6-OHDA treated 611 (D) and saline-treated (E) mice. Each recording performed in the striatum was obtained 612 in aCSF with an average of 3 recording sites per hemisphere and single pulse stimulation $613(400 \mu A, 1 \mathrm{~ms})$. Each recording performed in the SN/VTA was obtained in aCSF $+5 \mu M$ 614 nomifensine/sulpiride with pulse-train stimulation (30 pulses, $10 \mathrm{~Hz}, 400 \mu \mathrm{A}$ ). Error bars 615 represent +/- S.E.M. The statistical analysis was carried out using a t-test (contralateral 616 vs ipsilateral sides) (ns, non-significant; ***, $p<0.001 ; \#, p<0.0001)$.

618 Figure 5: Dopamine neurons express the calcium-sensors synaptotagmin 1, 4 and 7.

619 (A) Protocol used for double immunostaining for two primary antibodies from the same 620 host (adapted from a Jackson ImmunoResearch protocol:

621 https://www.jacksonimmuno.com/technical/products/protocols/double-labeling-same-

622 species-primary). Use of normal rabbit serum and unconjugated Fab fragments for 623 blocking after the first secondary. (B) Immunohistochemistry of midbrain and striatal 624 slices of adult DAT ${ }^{\text {IREScre }}$ heterozygote mice showing colocalization of VMAT2 and either 
625 Syt1, Syt4 or Syt7 in DAergic neurons. Scale bar $=20 \mu \mathrm{m}$. Control images were obtained

626 using the full protocol without the use of the second primary antibody (in the midbrain). (ns, non-significant; ***, $p<0.001 ; \#, p<0.0001$ ). The bold number represents the number of slices recorded / number of animals used.

640 Syt4 immunostaining of adult Syt4 WT (+/+) and $K O(-/-)$ mesencephalon showing the specificity of the Syt4 antibody. (B) TH and Syt7 immunostaining of adult Syt7 WT (+/+)

642 and $\mathrm{KO}$ (-/-) mice showing a strong reduction in signal, with some remaining background 643 signal in the KO animals. The anti-Syt7 antibody was generated against a recombinant 644 peptide comprising amino acids 46-133 of the unique Syt7 spacer domain ${ }^{66}$. The 645 targeting vector generated a stop codon after the position coding for amino acid 83 in 646 exon 4 (Fig. S2), thus making it possible that the remaining signal corresponds to a 647 short, mutated protein comprising the lumenal domain, the transmembrane region, and 
648 only a fraction of the spacer domain. (C) Representative striatal brain slices recorded

649 during FSCV experiments in WT and Syt4 constitutive KO mice. Red arrow indicates

650 obvious neurodevelopmental defects at the level of the anterior commissure and the

651 corpus callosum in $\mathrm{KO}$ animals.

652 Supplementary figure 2: No compensatory changes in Syt1, Syt4, Syt7, Syt11 mRNA

653 in Syt4 and Syt7 constitutive KO mice (A and B) Schematic representation of the

654 construction of Syt4 and Syt7 KO (-/-) mice. The primers used in qRT PCR for amplifying

655 the deleted region of each gene are indicated. ( $C$ and $\boldsymbol{D})$ Relative changes of $m R N A$

656 levels measured by qRT-PCR in Syt7 (C) and Syt4 (D) KO mice. Ct values (mean of

657 duplicate repeats) of Syt1, 4, 5, 7 and $11 \mathrm{mRNA}$ levels were normalized to the Ct value of

658 GAPDH in the same samples. Error bars represent +/- S.E.M. The statistical analysis

659 was carried out using a t-test (WT vs KO samples) (**, $p<0.01$; \#, $p<0.0001$ ). 


\section{Author contributions}

662 All authors participated in the design of experiments, data analysis, and interpretation.

663 CD performed qRT PCR experiments. NF performed double immunostaining 664 experiments. WK designed genotyping primers. BDL and LET wrote the manuscript.

\section{Conflict of interest}

666 The authors declare that they have no conflict of interest.

\section{Acknowledgements}

669 We thank Dr. Wade G Regehr (Harvard Medical School) for providing the Syt7

670 constitutive KO mice, Dr. Gary Miller (Columbia University) for providing the VMAT2

671 antibody and Marie-Josée Bourque for managing the mouse colonies and performing

672 mouse genotyping. This work was funded by the National Sciences and Engineering

673 Research Council of Canada (NSERC, grant RGPIN-2020-05279) to LET. LET also

674 received support from the Krembil Foundation, the Brain Canada Foundation and the

675 Henry and Berenice Kaufmann Foundation. BDL received a graduate student award from

676 Parkinson Canada. CD received a studentship from the Fonds de la Recherche du Québec

677 en Santé (FRQS). 


\section{REFERENCES}

682 (1) Schultz, W. Multiple Dopamine Functions at Different Time Courses. Annu. Rev.

Neurosci. 2007, 30 (1), 259-288.

https://doi.org/10.1146/annurev.neuro.28.061604.135722.

(2) Surmeier, D. J.; Graves, S. M.; Shen, W. Dopaminergic Modulation of Striatal

(3) Liu, C.; Kaeser, P. S. Mechanisms and Regulation of Dopamine Release. Curr. Opin. Neurobiol. 2019, 57, 46-53. https://doi.org/10.1016/j.conb.2019.01.001.

(4) Cragg, S.; Rice, M. E.; Greenfield, S. A. Heterogeneity of Electrically Evoked Striatum. J. Neurophysiol. 1997, 77 (2), 863-873. https://doi.org/10.1152/jn.1997.77.2.863.

(5) Rice, M. E.; Cragg, S. J.; Greenfield, S. A. Characteristics of Electrically Evoked Somatodendritic Dopamine Release in Substantia Nigra and Ventral Tegmental Area in Vitro. J. Neurophysiol. 1997, 77 (2), 853-862.

(6) Elverfors, A.; Jonason, J.; Jonason, G.; Nissbrandt, H. Effects of Drugs Interfering with Sodium Channels and Calcium Channels on the Release of Endogenous Dopamine from Superfused Substantia Nigra Slices. Synap. N. Y. N 1997, 26 (4), 359-369. https://doi.org/10.1002/(SICI)1098-2396(199708)26:4<359::AIDSYN4>3.0.CO;2-5. 
703 (7) Beckstead, M. J.; Grandy, D. K.; Wickman, K.; Williams, J. T. Vesicular Dopamine

704 Release Elicits an Inhibitory Postsynaptic Current in Midbrain Dopamine Neurons.

705 Neuron 2004, 42 (6), 939-946. https://doi.org/10.1016/j.neuron.2004.05.019.

706 (8) Cheramy, A.; Leviel, V.; Glowinski, J. Dendritic Release of Dopamine in the

Substantia Nigra. Nature 1981, 289 (5798), 537-543.

708

709

(9) Beckstead, M. J.; Grandy, D. K.; Wickman, K.; Williams, J. T. Vesicular Dopamine

Release Elicits an Inhibitory Postsynaptic Current in Midbrain Dopamine Neurons.

Neuron 2004, 42 (6), 939-946. https://doi.org/10.1016/j.neuron.2004.05.019.

(10) Bergquist, F.; Shahabi, H. N.; Nissbrandt, H. Somatodendritic Dopamine Release in

Rat Substantia Nigra Influences Motor Performance on the Accelerating Rod. Brain

(11) Andersson, D. R.; Nissbrandt, H.; Bergquist, F. Partial Depletion of Dopamine in

Neurotransmission. Eur. J. Neurosci. 2006, 24 (2), 617-624.

https://doi.org/10.1111/j.1460-9568.2006.04953.x.

(12) Falkenburger, B. H.; Barstow, K. L.; Mintz, I. M. Dendrodendritic Inhibition https://doi.org/10.1126/science.1060645.

(13) Chen, B. T.; Rice, M. E. Novel Ca2+ Dependence and Time Course of 
725 (14) Cragg, S. J.; Nicholson, C.; Kume-Kick, J.; Tao, L.; Rice, M. E. Dopamine-

726 Mediated Volume Transmission in Midbrain Is Regulated by Distinct Extracellular

727 Geometry and Uptake. J. Neurophysiol. 2001, 85 (4), 1761-1771.

728 https://doi.org/10.1152/jn.2001.85.4.1761.

729 (15) Santiago, M.; Westerink, B. H. Characterization and Pharmacological

730 Responsiveness of Dopamine Release Recorded by Microdialysis in the Substantia

$731 \quad$ Nigra of Conscious Rats. J. Neurochem. 1991, 57 (3), 738-747.

732 https://doi.org/10.1111/j.1471-4159.1991.tb08214.x.

733 (16) Elverfors, A.; Nissbrandt, H. Effects of D-Amphetamine on Dopaminergic

734 Neurotransmission; a Comparison between the Substantia Nigra and the Striatum.

735 Neuropharmacology 1992, 31 (7), 661-670. https://doi.org/10.1016/0028-

736 3908(92)90144-e.

737 (17) Hoffman, A. F.; Lupica, C. R.; Gerhardt, G. A. Dopamine Transporter Activity in 738 the Substantia Nigra and Striatum Assessed by High-Speed Chronoamperometric 739 Recordings in Brain Slices. J. Pharmacol. Exp. Ther. 1998, 287 (2), 487-496.

740 (18) Fortin, G. D.; Desrosiers, C. C.; Yamaguchi, N.; Trudeau, L. E. Basal

741 Somatodendritic Dopamine Release Requires Snare Proteins. J. Neurochem. 2006, $74296(6), 1740-1749$. https://doi.org/10.1111/j.1471-4159.2006.03699.x.

743 (19) Mendez, J. A.; Bourque, M.-J.; Fasano, C.; Kortleven, C.; Trudeau, L.-E.

744 Somatodendritic Dopamine Release Requires Synaptotagmin 4 and 7 and the 745 Participation of Voltage-Gated Calcium Channels. J. Biol. Chem. 2011, 286 (27), 23968-23937. https://doi.org/10.1074/jbc.M111.218032. 
747 (20) Yee, A. G.; Forbes, B.; Cheung, P.-Y.; Martini, A.; Burrell, M. H.; Freestone, P. S.;

748 Lipski, J. Action Potential and Calcium Dependence of Tonic Somatodendritic Dopamine Release in the Substantia Nigra Pars Compacta. J. Neurochem. 2019, 148 (4), 462-479. https://doi.org/10.1111/jnc.14587.

751

(21) Robertson, G. S.; Damsma, G.; Fibiger, H. C. Characterization of Dopamine Release in the Substantia Nigra by in Vivo Microdialysis in Freely Moving Rats. $J$. Neurosci. Off. J. Soc. Neurosci. 1991, 11 (7), 2209-2216.

(22) Rice, M. E.; Richards, C. D.; Nedergaard, S.; Hounsgaard, J.; Nicholson, C.; Greenfield, S. A. Direct Monitoring of Dopamine and 5-HT Release in Substantia Nigra and Ventral Tegmental Area in Vitro. Exp. Brain Res. 1994, 100 (3), 395406. https://doi.org/10.1007/bf02738400.

(23) Heeringa, M. J.; Abercrombie, E. D. Biochemistry of Somatodendritic Dopamine Release in Substantia Nigra: An in Vivo Comparison with Striatal Dopamine Release. J. Neurochem. 1995, 65 (1), 192-200. https://doi.org/10.1046/j.14714159.1995.65010192.x.

(24) Ford, C. P.; Gantz, S. C.; Phillips, P. E. M.; Williams, J. T. Control of Extracellular Dopamine at Dendrite and Axon Terminals. J. Neurosci. Off. J. Soc. Neurosci. 2010, 30 (20), 6975-6983. https://doi.org/10.1523/JNEUROSCI.1020-10.2010.

(25) Bergquist, F.; Niazi, H. S.; Nissbrandt, H. Evidence for Different Exocytosis Pathways in Dendritic and Terminal Dopamine Release in Vivo. Brain Res. 2002, 950 (1-2), 245-253. https://doi.org/10.1016/s0006-8993(02)03047-0. 
768 (26) Ovsepian, S. V.; Dolly, J. O. Dendritic SNAREs Add a New Twist to the Old

Neuron Theory. Proc. Natl. Acad. Sci. 2011, 108 (48), 19113-19120.

https://doi.org/10.1073/pnas.1017235108.

771 (27) Nirenberg, M. J.; Chan, J.; Liu, Y.; Edwards, R. H.; Pickel, V. M. Ultrastructural

Neurons: Potential Sites for Somatodendritic Storage and Release of Dopamine. $J$. 04135.1996.

776 (28) Beckstead, M. J.; Ford, C. P.; Phillips, P. E. M.; Williams, J. T. Presynaptic

(6), 1479-1488. https://doi.org/10.1111/j.1460-9568.2007.05775.x.

779

780

781

782

783
(29) Ford, C. P.; Phillips, P. E. M.; Williams, J. T. The Time Course of Dopamine Transmission in the Ventral Tegmental Area. J. Neurosci. 2009, 29 (42), 1334413352. https://doi.org/10.1523/JNEUROSCI.3546-09.2009.

(30) Courtney, N. A.; Mamaligas, A. A.; Ford, C. P. Species Differences in Somatodendritic Dopamine Transmission Determine D2-Autoreceptor-Mediated Inhibition of Ventral Tegmental Area Neuron Firing. J. Neurosci. 2012, 32 (39), 13520-13528. https://doi.org/10.1523/JNEUROSCI.2745-12.2012.

(31) Gantz, S. C.; Bunzow, J. R.; Williams, J. T. Spontaneous Inhibitory Synaptic Currents Mediated by a G Protein-Coupled Receptor. Neuron 2013, 78 (5), 807812. https://doi.org/10.1016/j.neuron.2013.04.013. 
789

790

(32) Cheng, H.-C.; Ulane, C. M.; Burke, R. E. Clinical Progression in Parkinson’s Disease and the Neurobiology of Axons. Ann. Neurol. 2010, 67 (6), 715-725. https://doi.org/10.1002/ana.21995.

(33) Sarre, S.; Yuan, H.; Jonkers, N.; Van Hemelrijck, A.; Ebinger, G.; Michotte, Y. In Vivo Characterization of Somatodendritic Dopamine Release in the Substantia Nigra of 6-Hydroxydopamine-Lesioned Rats. J. Neurochem. 2004, 90 (1), 29-39. https://doi.org/10.1111/j.1471-4159.2004.02471.x.

(34) Stott, S. R. W.; Barker, R. A. Time Course of Dopamine Neuron Loss and Glial Response in the 6-OHDA Striatal Mouse Model of Parkinson's Disease. Eur. J. Neurosci. 2014, 39 (6), 1042-1056. https://doi.org/10.1111/ejn.12459.

(35) Dean, C.; Dunning, F. M.; Liu, H.; Bomba-Warczak, E.; Martens, H.; Bharat, V.; Ahmed, S.; Chapman, E. R. Axonal and Dendritic Synaptotagmin Isoforms Revealed by a PHluorin-Syt Functional Screen. Mol. Biol. Cell 2012, 23 (9), 17151727. https://doi.org/10.1091/mbc.E11-08-0707.

(36) Ducrot, C.; Bourque, M.-J.; Delmas, C. V. L.; Racine, A.-S.; Bello, D. G.; DelignatLavaud, B.; Lycas, M. D.; Fallon, A.; Michaud-Tardif, C.; Nanni, S. B.; Herborg, F.; Gether, U.; Nanci, A.; Takahashi, H.; Parent, M.; Trudeau, L.-E. Dopaminergic Neurons Establish a Distinctive Axonal Arbor with a Majority of Non-Synaptic Terminals. bioRxiv 2020, 2020.05.11.088351. https://doi.org/10.1101/2020.05.11.088351.

(37) Banerjee, A.; Lee, J.; Nemcova, P.; Liu, C.; Kaeser, P. S. Synaptotagmin-1 Is the Ca2+ Sensor for Fast Striatal Dopamine Release. eLife 2020, 9, e58359. https://doi.org/10.7554/eLife.58359. 
812 (38) Ferguson, G. D.; Anagnostaras, S. G.; Silva, A. J.; Herschman, H. R. Deficits in

813

Memory and Motor Performance in Synaptotagmin IV Mutant Mice. Proc. Natl.

Acad. Sci. U. S. A. 2000, 97 (10), 5598-5603.

https://doi.org/10.1073/pnas.100104597.

(39) Chakrabarti, S.; Kobayashi, K. S.; Flavell, R. A.; Marks, C. B.; Miyake, K.; Liston, D. R.; Fowler, K. T.; Gorelick, F. S.; Andrews, N. W. Impaired Membrane Resealing and Autoimmune Myositis in Synaptotagmin VII-Deficient Mice. J. Cell Biol. 2003, 162 (4), 543-549. https://doi.org/10.1083/jcb.200305131.

(40) Martel, P.; Leo, D.; Fulton, S.; Bérard, M.; Trudeau, L.-E. Role of Kv1 Potassium Channels in Regulating Dopamine Release and Presynaptic D2 Receptor Function. PloS One 2011, 6 (5), e20402. https://doi.org/10.1371/journal.pone.0020402.

(41) Livak, K. J.; Schmittgen, T. D. Analysis of Relative Gene Expression Data Using Real-Time Quantitative PCR and the 2(-Delta Delta C(T)) Method. Methods San Diego Calif 2001, 25 (4), 402-408. https://doi.org/10.1006/meth.2001.1262.

(42) Robinson, D. L.; Venton, B. J.; Heien, M. L. A. V.; Wightman, R. M. Detecting Subsecond Dopamine Release with Fast-Scan Cyclic Voltammetry in Vivo. Clin. Chem. 2003, 49 (10), 1763-1773. https://doi.org/10.1373/49.10.1763.

(43) Yang, H.; Michael, A. C. In Vivo Fast-Scan Cyclic Voltammetry of Dopamine near Microdialysis Probes. In Electrochemical Methods for Neuroscience; Michael, A. C., Borland, L. M., Eds.; Frontiers in Neuroengineering; CRC Press/Taylor \& Francis: Boca Raton (FL), 2007.

(44) John, C. E.; Jones, S. R. Fast Scan Cyclic Voltammetry of Dopamine and Serotonin in Mouse Brain Slices. In Electrochemical Methods for Neuroscience; Michael, A. 
(45) O’Neill, B.; Patel, J. C.; Rice, M. E. Characterization of Optically and Electrically Evoked Dopamine Release in Striatal Slices from Digenic Knock-in Mice with DAT-Driven Expression of Channelrhodopsin. ACS Chem. Neurosci. 2017, 8 (2), 310-319. https://doi.org/10.1021/acschemneuro.6b00300.

841
(46) Congar, P.; Bergevin, A.; Trudeau, L.-E. D2 Receptors Inhibit the Secretory Process Downstream From Calcium Influx in Dopaminergic Neurons: Implication of K+ Channels. J. Neurophysiol. 2002, 87 (2), 1046-1056. https://doi.org/10.1152/jn.00459.2001.

(47) Kristensen, A. S.; Andersen, J.; Jørgensen, T. N.; Sørensen, L.; Eriksen, J.; Loland, C. J.; Strømgaard, K.; Gether, U. SLC6 Neurotransmitter Transporters: Structure, Function, and Regulation. Pharmacol. Rev. 2011, 63 (3), 585-640. https://doi.org/10.1124/pr.108.000869.

(48) Lebowitz, J. J.; Khoshbouei, H. Heterogeneity of Dopamine Release Sites in Health and Degeneration. Neurobiol. Dis. 2020, 134, 104633. https://doi.org/10.1016/j.nbd.2019.104633.

(49) Chen, B. T.; Patel, J. C.; Moran, K. A.; Rice, M. E. Differential Calcium Dependence of Axonal versus Somatodendritic Dopamine Release, with Characteristics of Both in the Ventral Tegmental Area. Front. Syst. Neurosci. 2011, 5, 39. https://doi.org/10.3389/fnsys.2011.00039.

(50) Nair-Roberts, R. G.; Chatelain-Badie, S. D.; Benson, E.; White-Cooper, H.; Bolam, J. P.; Ungless, M. A. Stereological Estimates of Dopaminergic, GABAergic and 
Glutamatergic Neurons in the Ventral Tegmental Area, Substantia Nigra and

Retrorubral Field in the Rat. Neuroscience 2008, 152 (4-2), 1024-1031. https://doi.org/10.1016/j.neuroscience.2008.01.046.

861

862
(51) Deutch, A. Y.; Goldstein, M.; Baldino, F.; Roth, R. H. Telencephalic Projections of the A8 Dopamine Cell Group. Ann. N. Y. Acad. Sci. 1988, 537, 27-50. https://doi.org/10.1111/j.1749-6632.1988.tb42095.x.

(52) Bayer, V. E.; Pickel, V. M. Ultrastructural Localization of Tyrosine Hydroxylase in the Rat Ventral Tegmental Area: Relationship between Immunolabeling Density and Neuronal Associations. J. Neurosci. Off. J. Soc. Neurosci. 1990, 10 (9), 29963013.

(53) Fernandes Xavier, F. G.; Doucet, G.; Geffard, M.; Descarries, L. Dopamine Neoinnervation in the Substantia Nigra and Hyperinnervation in the Interpeduncular Nucleus of Adult Rat Following Neonatal Cerebroventricular Administration of 6Hydroxydopamine. Neuroscience 1994, 59 (1), 77-87. https://doi.org/10.1016/03064522(94)90100-7.

(54) Burke, R. E.; O’Malley, K. Axon Degeneration in Parkinson's Disease. Exp. Neurol. 2013, 246, 72-83. https://doi.org/10.1016/j.expneurol.2012.01.011.

(55) Robertson, G. S.; Robertson, H. A. Evidence That L-Dopa-Induced Rotational Behavior Is Dependent on Both Striatal and Nigral Mechanisms. J. Neurosci. 1989, 9 (9), 3326-3331. https://doi.org/10.1523/JNEUROSCI.09-09-03326.1989.

(56) Crocker, A. D. The Regulation of Motor Control: An Evaluation of the Role of Dopamine Receptors in the Substantia Nigra. Rev. Neurosci. 1997, 8 (1), 55-76. 
880

881

(57) Andersson, D. R.; Nissbrandt, H.; Bergquist, F. Partial Depletion of Dopamine in Substantia Nigra Impairs Motor Performance without Altering Striatal Dopamine Neurotransmission. Eur. J. Neurosci. 2006, 24 (2), 617-624. https://doi.org/10.1111/j.1460-9568.2006.04953.x.

(58) Fahn, S. The Medical Treatment of Parkinson Disease from James Parkinson to George Cotzias. Mov. Disord. Off. J. Mov. Disord. Soc. 2015, 30 (1), 4-18. https://doi.org/10.1002/mds.26102.

(59) Parmar, M.; Torper, O.; Drouin-Ouellet, J. Cell-Based Therapy for Parkinson's Disease: A Journey through Decades toward the Light Side of the Force. Eur. J. Neurosci. 2019, 49 (4), 463-471. https://doi.org/10.1111/ejn.14109.

(60) Shimojo, M.; Madara, J.; Pankow, S.; Liu, X.; Yates, J.; Südhof, T. C.; Maximov, A. Synaptotagmin-11 Mediates a Vesicle Trafficking Pathway That Is Essential for Development and Synaptic Plasticity. Genes Dev. 2019, 33 (5-6), 365-376. https://doi.org/10.1101/gad.320077.118.

(61) von Poser, C.; Ichtchenko, K.; Shao, X.; Rizo, J.; Südhof, T. C. The Evolutionary Pressure to Inactivate. A Subclass of Synaptotagmins with an Amino Acid Substitution That Abolishes Ca2+ Binding. J. Biol. Chem. 1997, 272 (22), 1431414319. https://doi.org/10.1074/jbc.272.22.14314.

(62) Huynh, D. P.; Scoles, D. R.; Nguyen, D.; Pulst, S. M. The Autosomal Recessive Juvenile Parkinson Disease Gene Product, Parkin, Interacts with and Ubiquitinates Synaptotagmin XI. Hum. Mol. Genet. 2003, 12 (20), 2587-2597. https://doi.org/10.1093/hmg/ddg269. 
902 (63) International Parkinson Disease Genomics Consortium; Nalls, M. A.; Plagnol, V.;

903 Hernandez, D. G.; Sharma, M.; Sheerin, U.-M.; Saad, M.; Simón-Sánchez, J.;

Schulte, C.; Lesage, S.; Sveinbjörnsdóttir, S.; Stefánsson, K.; Martinez, M.; Hardy,

J.; Heutink, P.; Brice, A.; Gasser, T.; Singleton, A. B.; Wood, N. W. Imputation of

Sequence Variants for Identification of Genetic Risks for Parkinson's Disease: A

Meta-Analysis of Genome-Wide Association Studies. Lancet Lond. Engl. 2011, 377

908

(9766), 641-649. https://doi.org/10.1016/S0140-6736(10)62345-8.

909

(64) Wang, C.; Kang, X.; Zhou, L.; Chai, Z.; Wu, Q.; Huang, R.; Xu, H.; Hu, M.; Sun, X.; Sun, S.; Li, J.; Jiao, R.; Zuo, P.; Zheng, L.; Yue, Z.; Zhou, Z. Synaptotagmin-11

Pathology. Nat. Commun. 2018, 9 (1), 1-14. https://doi.org/10.1038/s41467-01702593-y.

(65) Robinson, B. G.; Cai, X.; Wang, J.; Bunzow, J. R.; Williams, J. T.; Kaeser, P. S. RIM Is Essential for Stimulated but Not Spontaneous Somatodendritic Dopamine Release in the Midbrain. eLife 2019, 8, e47972. https://doi.org/10.7554/eLife.47972.

(66) Sugita, S.; Han, W.; Butz, S.; Liu, X.; Fernández-Chacón, R.; Lao, Y.; Südhof, T. C. 

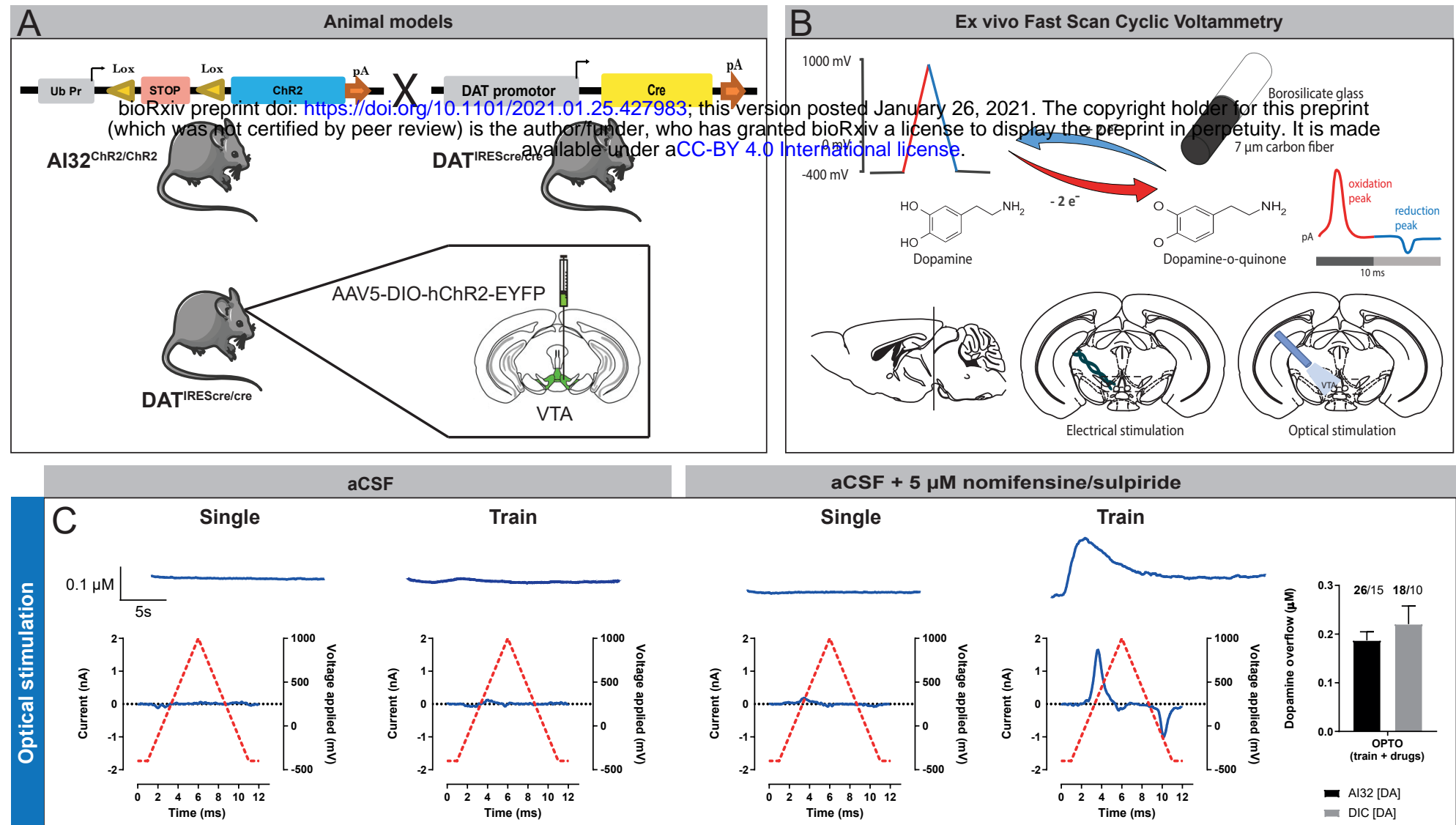

aCSF

aCSF $+5 \mu \mathrm{M}$ nomifensine/sulpiride
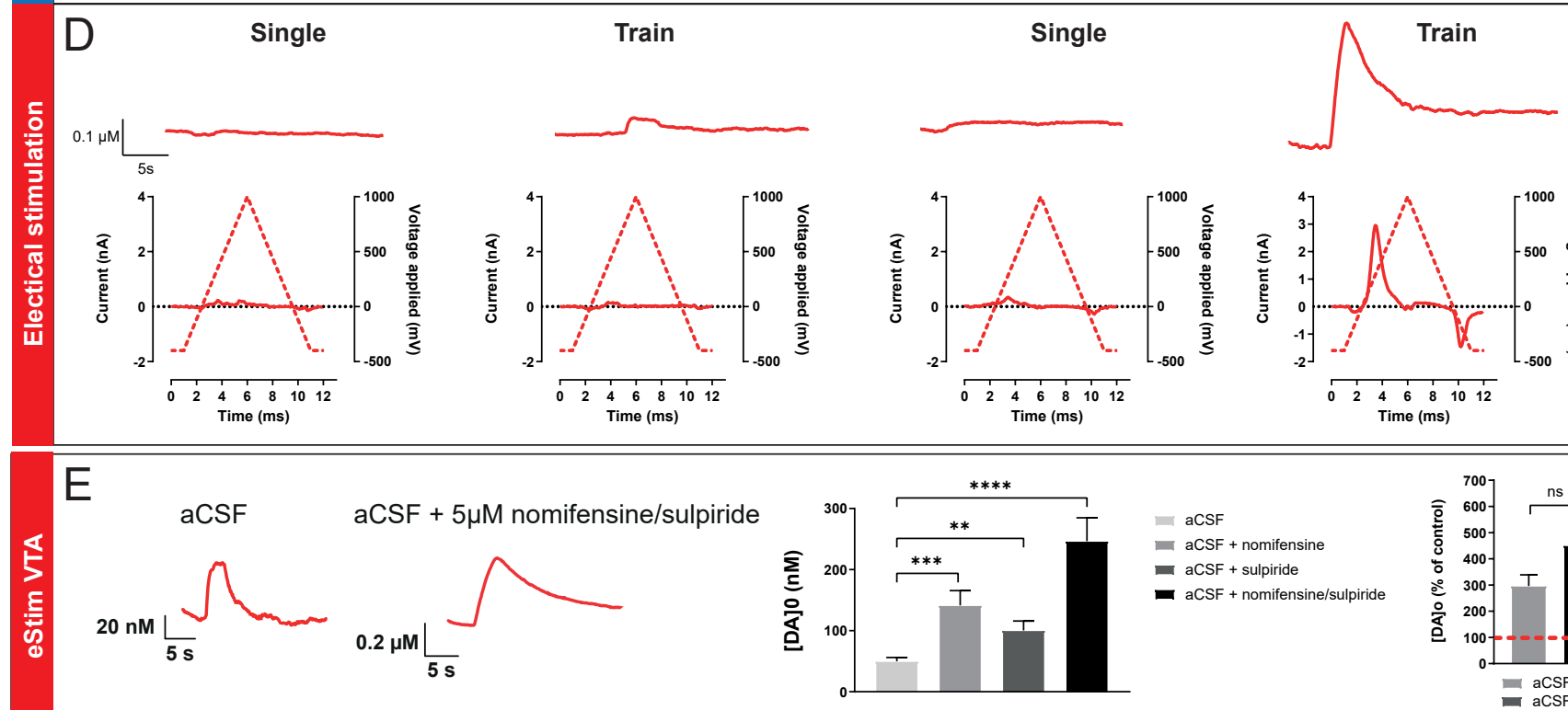

- aCSF + nomifensine

E aCSF + sulpiride

- aCSF + nomifensine/sulpiride
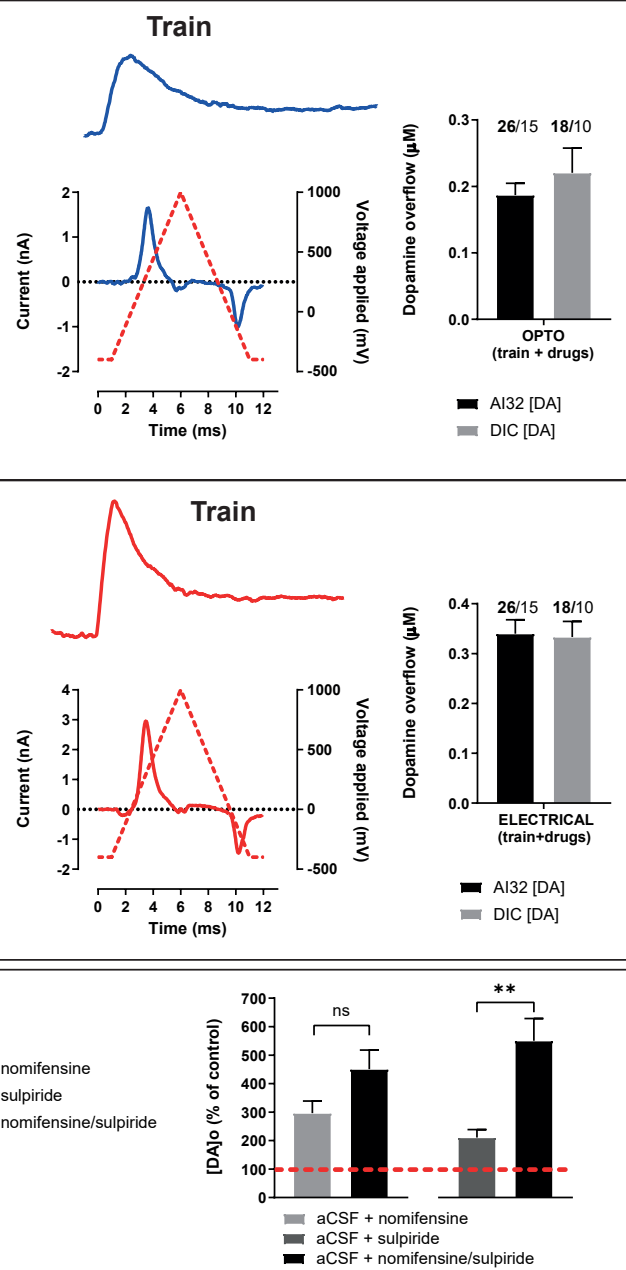


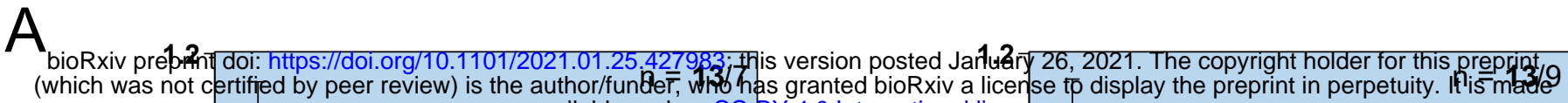
(which was a a

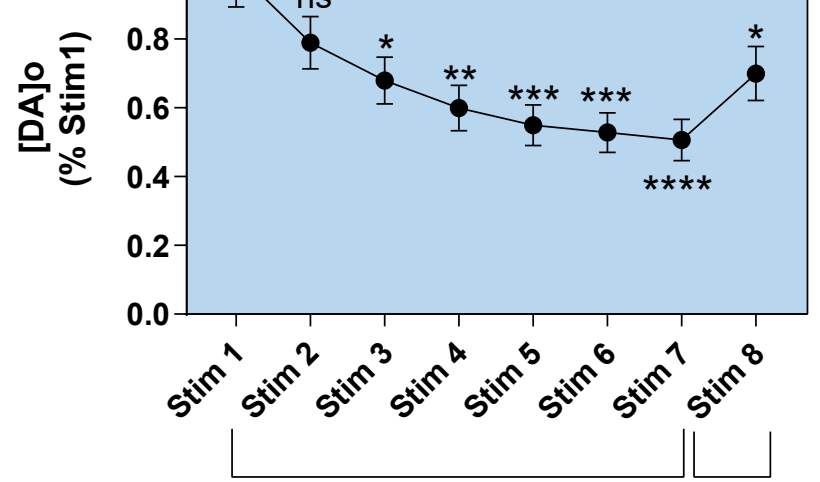

5 min inter-stimulation interval $20 \mathrm{~min}$

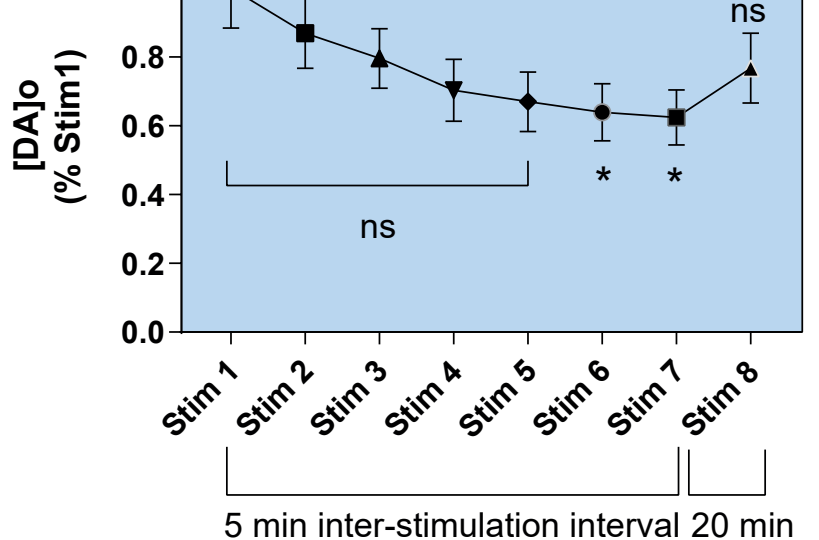

B
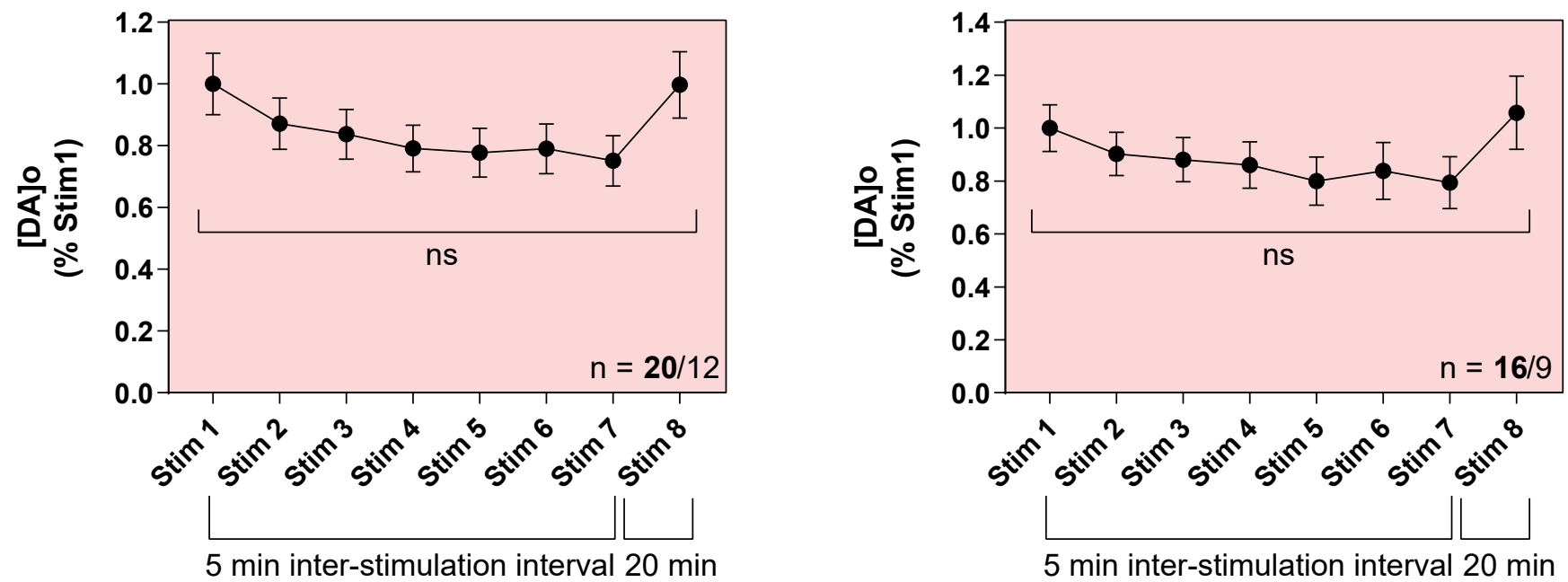
Slice placed in

$+5 \mu \mathrm{M}$ nomifensine/sulpiride
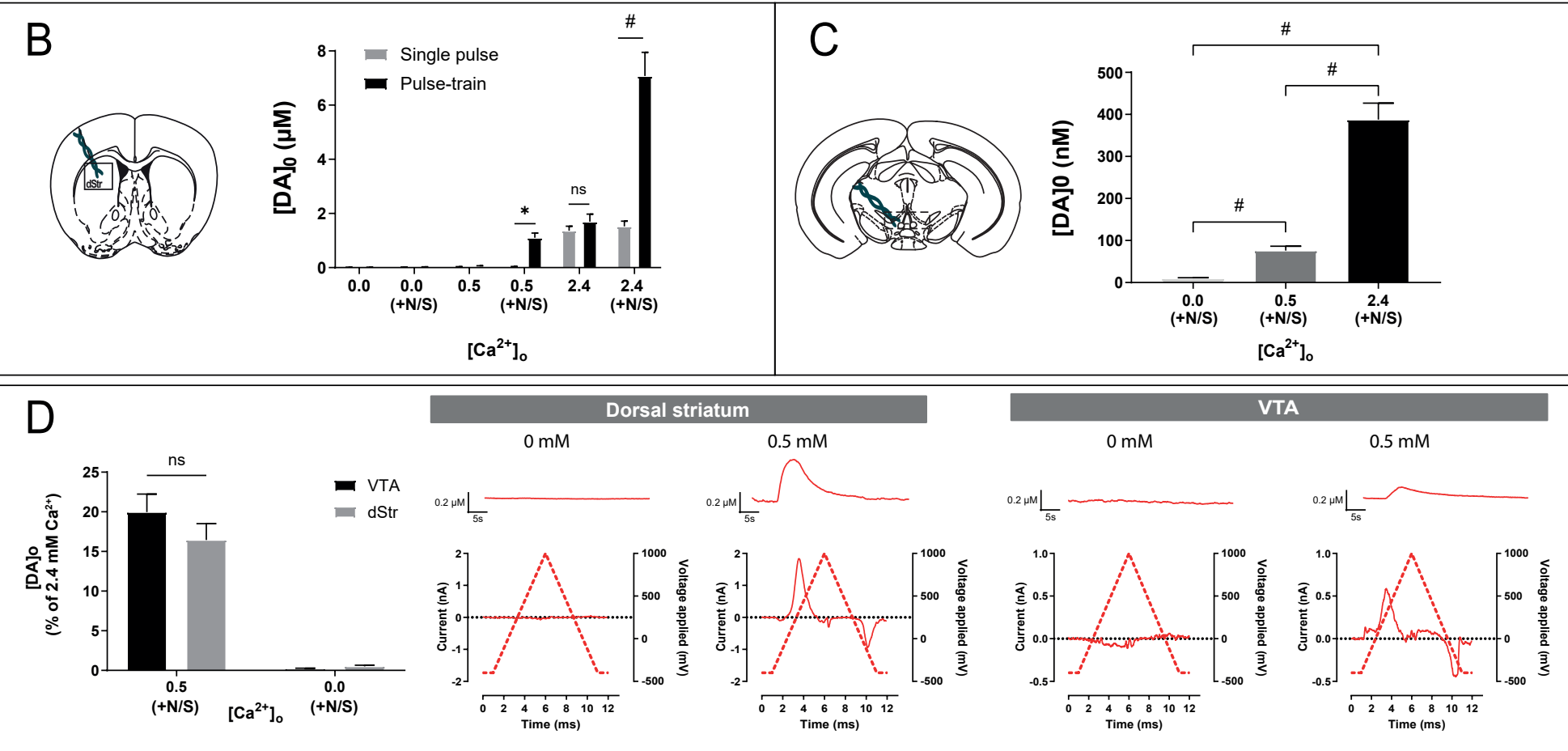
Fig.4

bioRxiv preprint d ji: https://doforg/10.1101/2021.01.25.427983; this version posted January 26, 2021. The copyright holder for this preprint (which was not cont of ofer yeview) is the author/funder, who has granted bioRxiv a license to displaly thepepreprint in perpetuity. It is made A

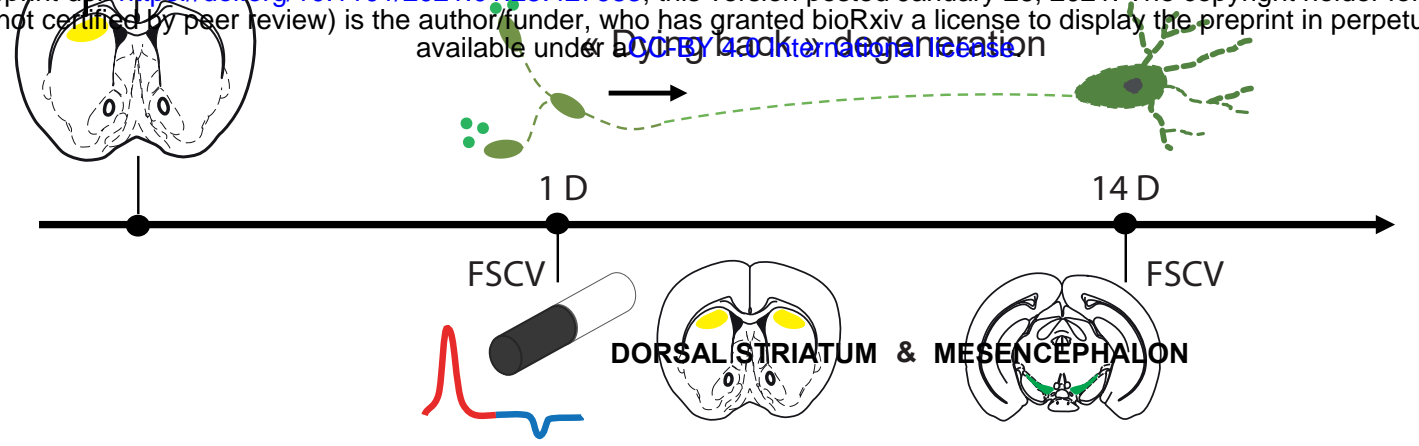

\section{6-OHDA}

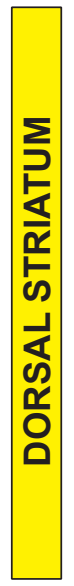

$\mathrm{B}$

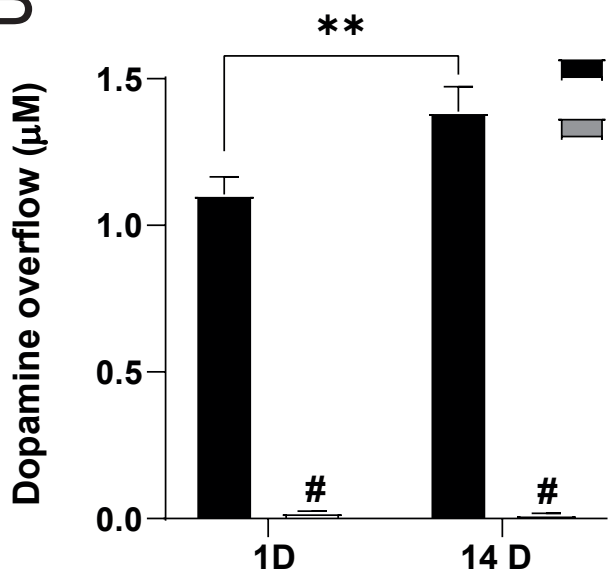

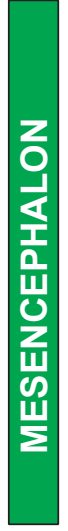

$\mathrm{D}$

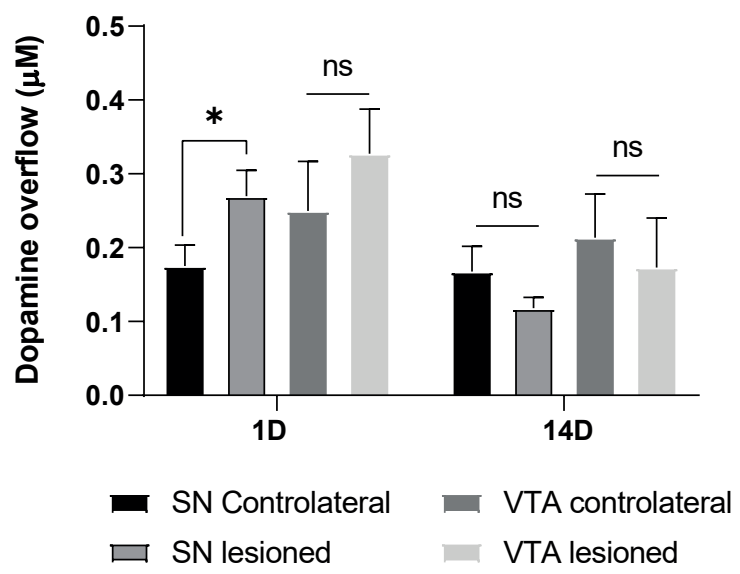

\section{SALINE}
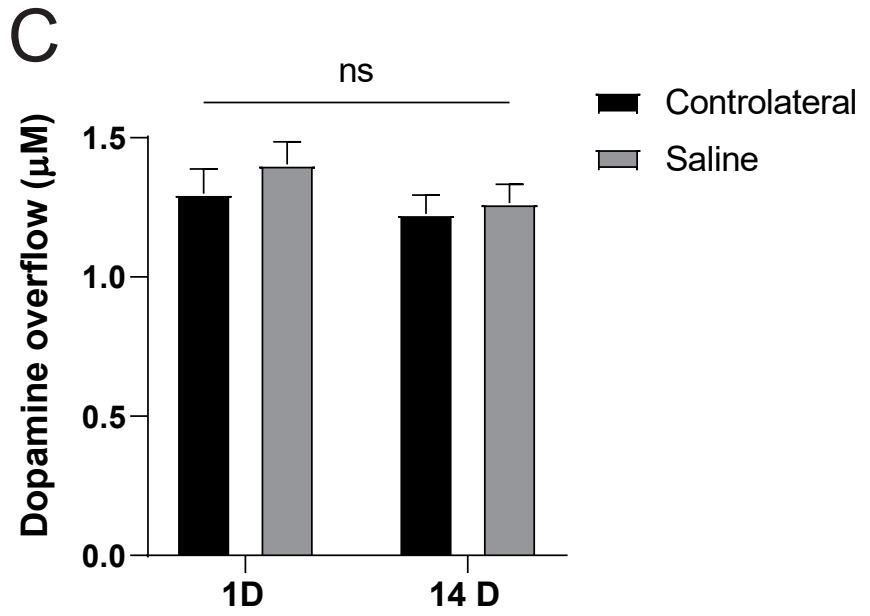

E

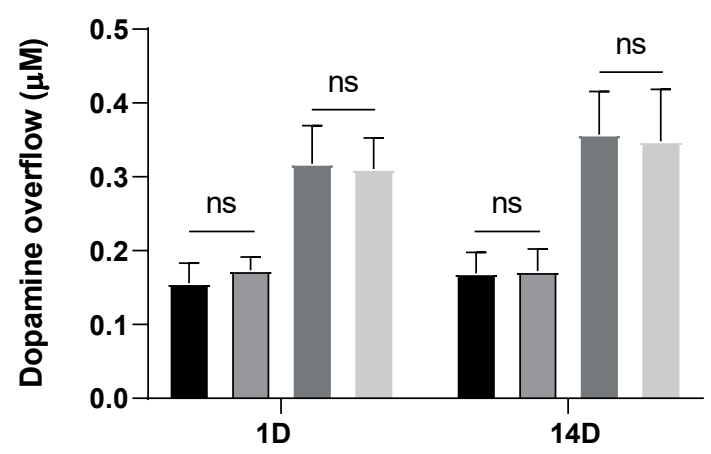

- SN Controlateral VTA controlateral

$\square$ SN Saline

- VTA Saline 
bioRXiv preprint doi: https://Goi.org/10.1101/2021.01325.427983; this verston posted January $26, \mathbf{5}_{2021}$. The copyright holder for this preprint (which was ngt certified by peer reviey) is the author/funder, who has granted biøRxiv a license to dişplay the preprint in perpefuity. It is made
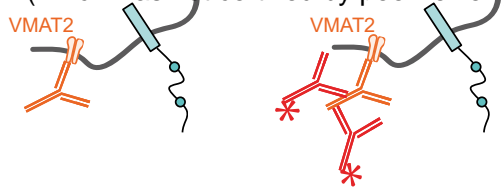

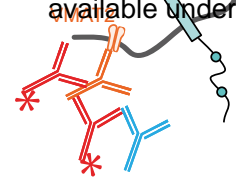

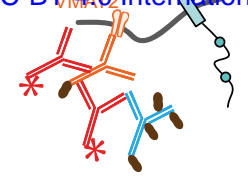
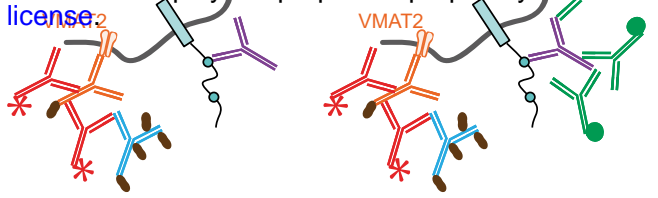

B

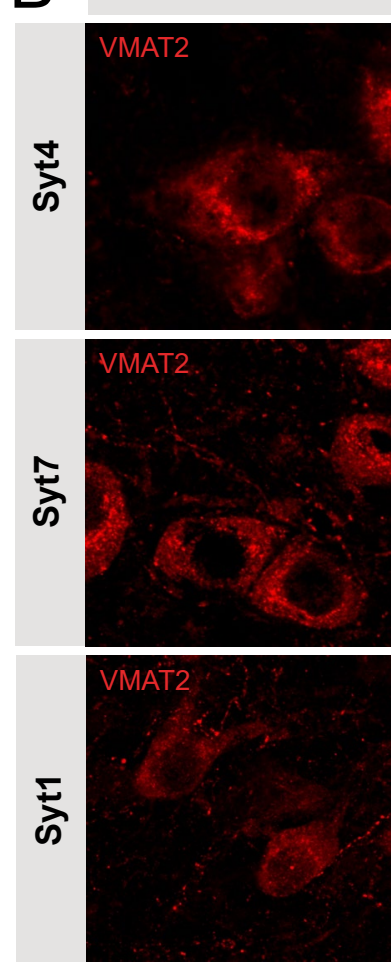

Midbrain
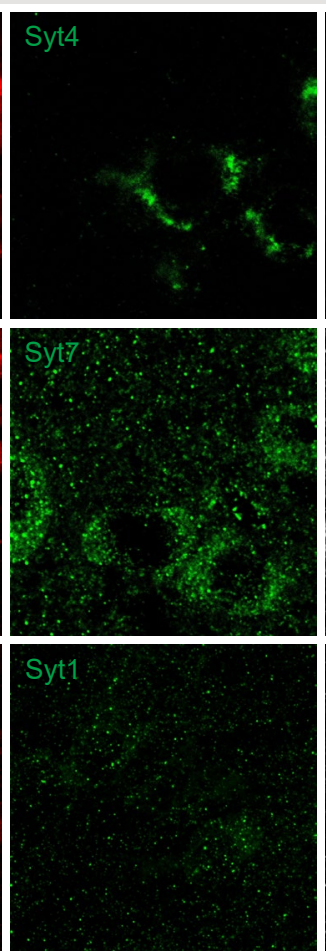

Syt4
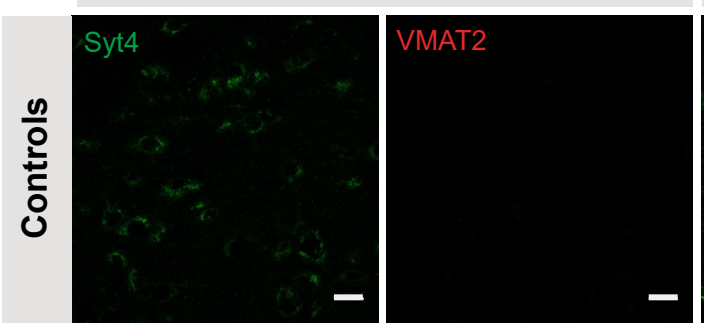
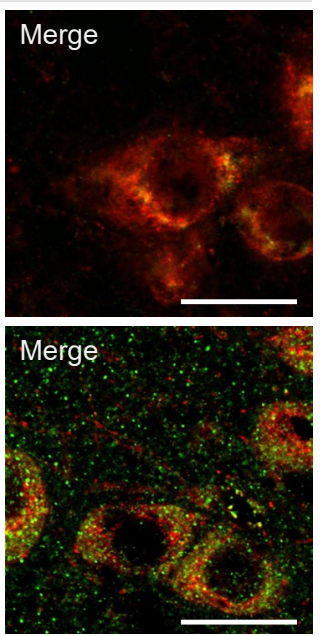

Merge

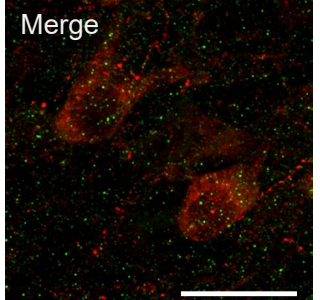

\section{Striatum}
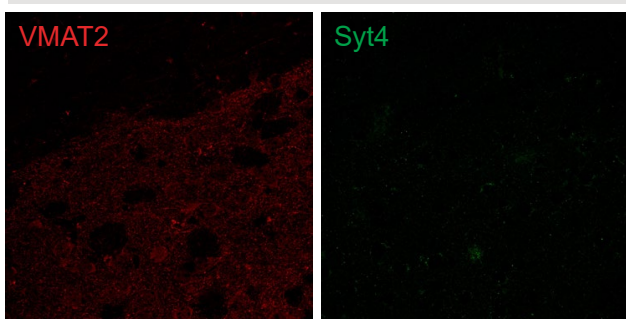

Merge
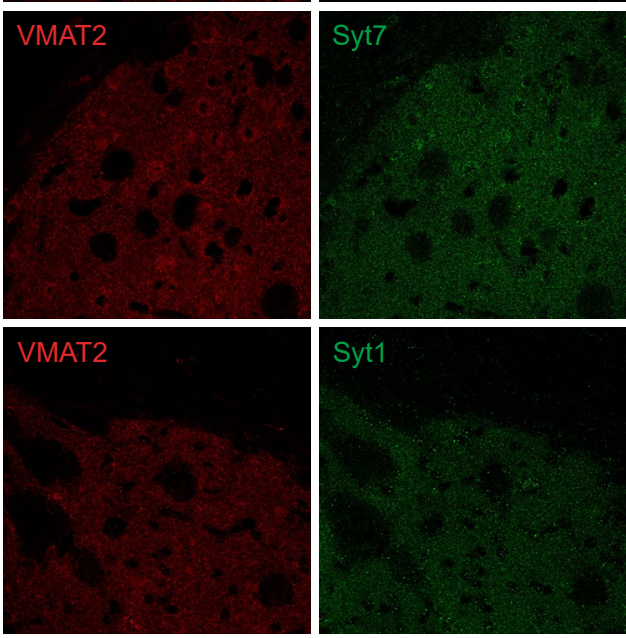

\section{Syt1}

Syt7

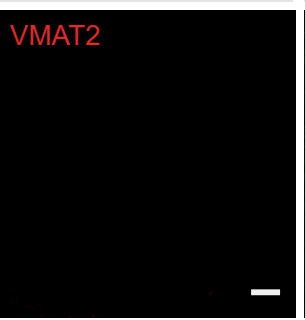

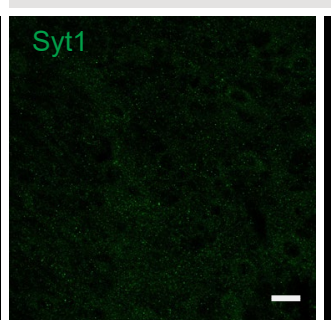

-
VMAT2

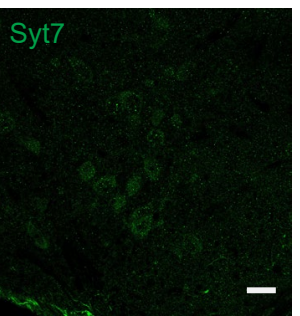

Merge

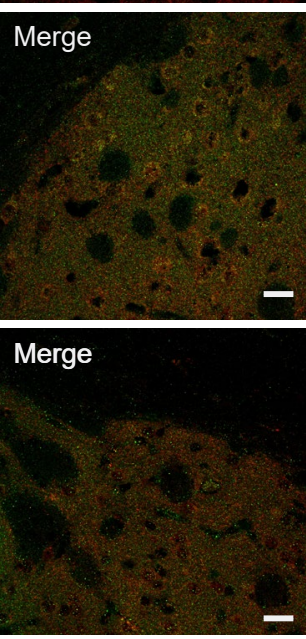

- 
Fig. 6

bioRxiv preprint doi: https://doi.prat10.1101/2021.01.25.427983; this version posted January 26, 2021. The copyright holder for this preprint (which was not certified beer reven) is the author/funder, who has granted bioRxiv a license to display the preprint in perpetuity. It is made
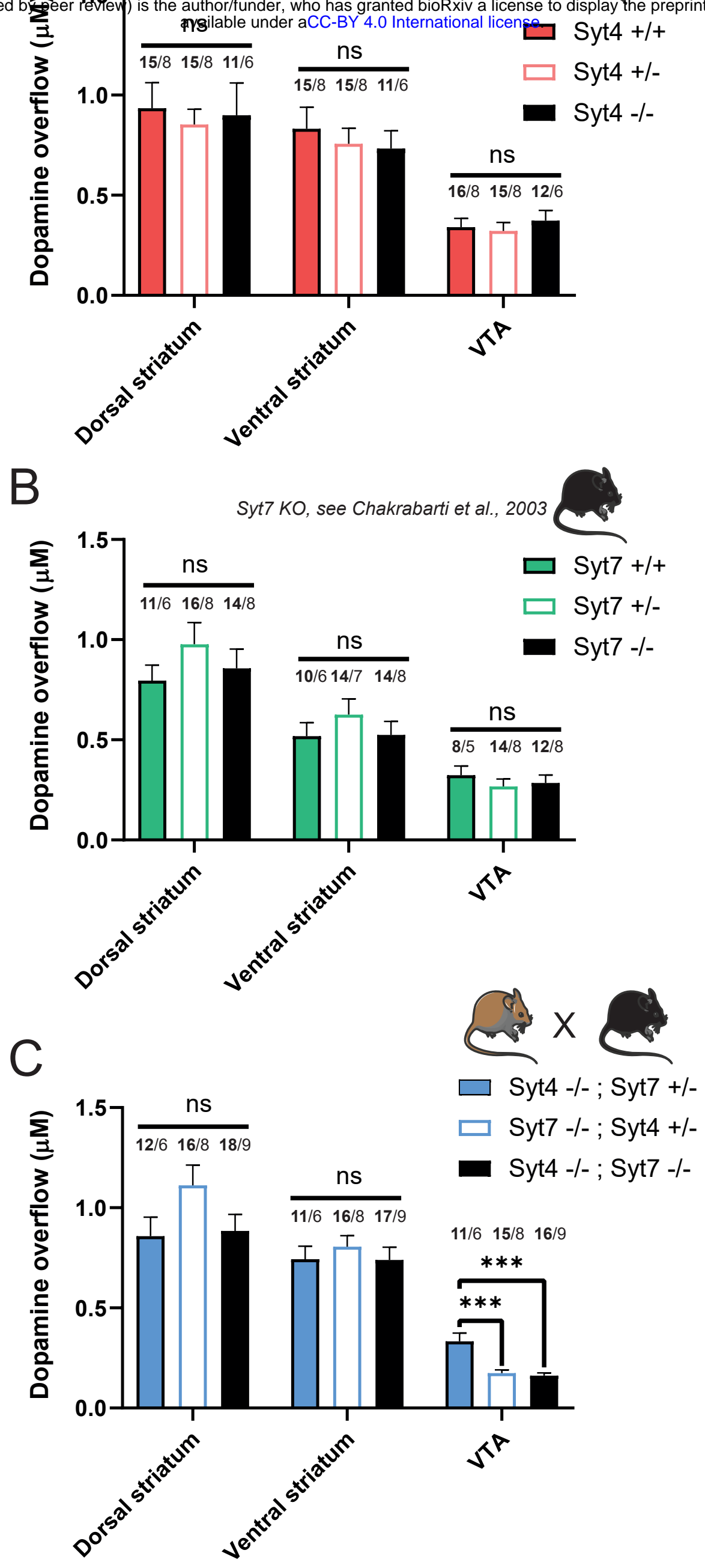


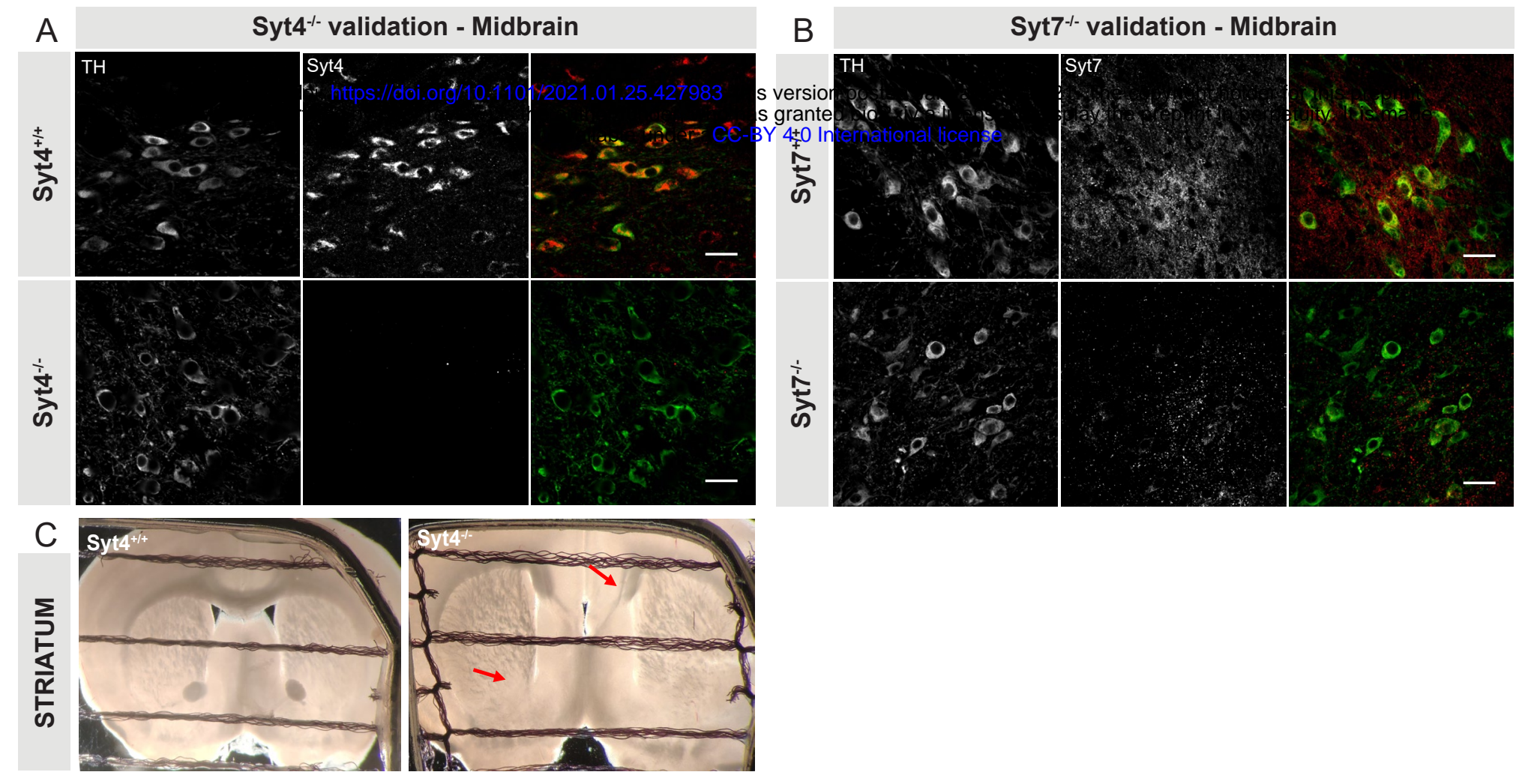

Fig. S1 
Fig.S2

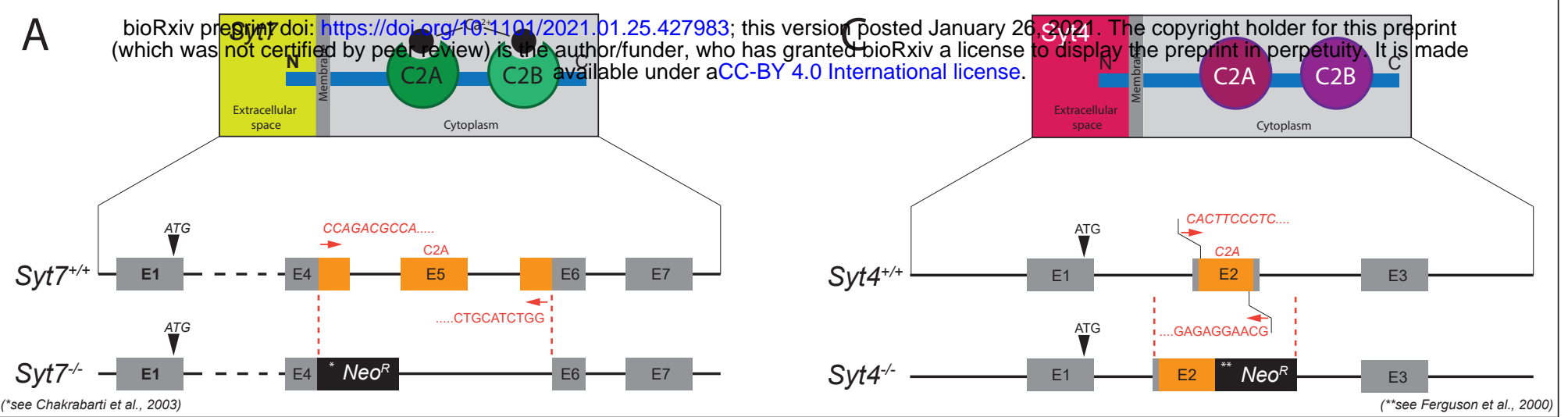

\section{mRNA quantifications of Syt-1, 4, 5, 11 in Syt-7 WT/KO mice and Syt-4 WT/KO mice}

B

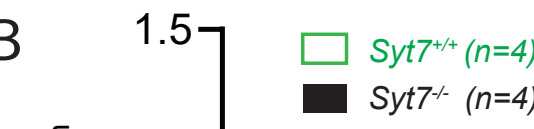

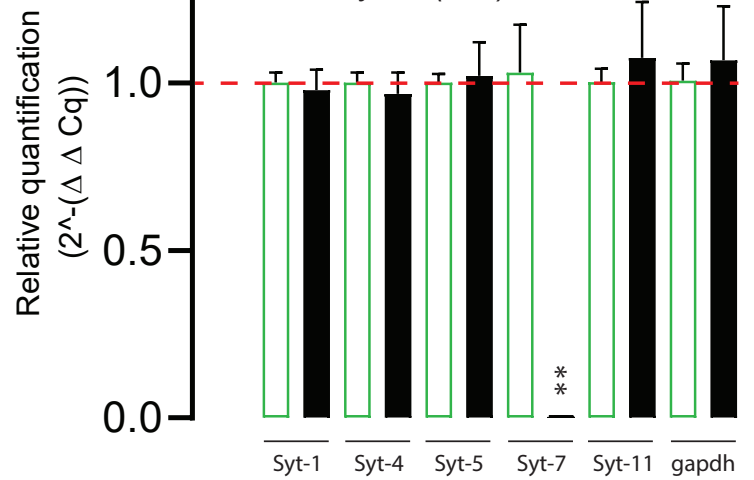

D

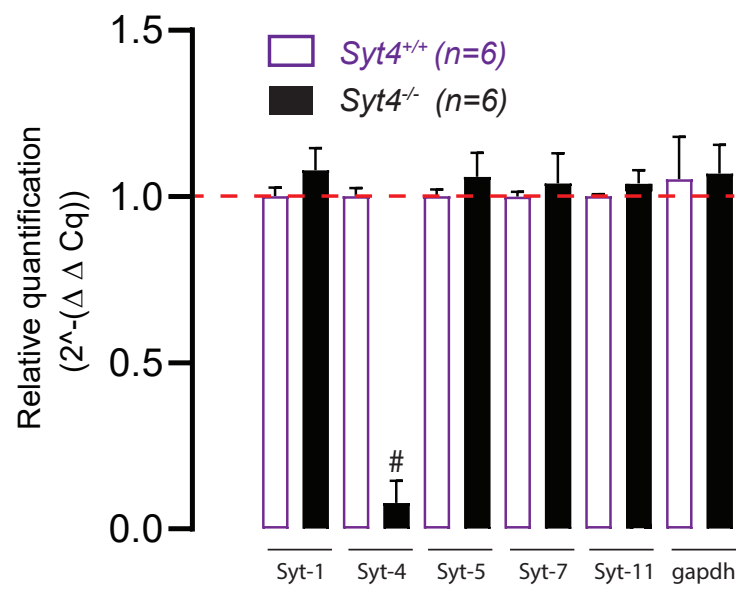

